\title{
Dissecting the fission yeast regulatory network reveals phase-specific control elements of its cell cycle Pierre R Bushel ${ }^{* \dagger 1,5}$, Nicholas A Heard ${ }^{\dagger 2}$, Roee Gutman ${ }^{3}$, Liwen Liu1, Shyamal D Peddada ${ }^{1}$ and Saumyadipta Pyne*4,6
}

Address: ${ }^{1}$ Biostatistics Branch, National Institute of Environmental Health Sciences, Research Triangle Park, NC 27709 USA, ${ }^{2}$ Department of Mathematics, Imperial College, London, UK, ${ }^{3}$ Department of Statistics, Harvard University, Cambridge, MA 02138, USA, ${ }^{4}$ Broad Institute of the Massachusetts Institute of Technology and Harvard University, 7 Cambridge Center, Cambridge, MA 02142, USA, ${ }^{5}$ Department of Statistics and Department of Environmental Health, Harvard School of Public Health, Harvard University, Boston, MA 02115, USA and ${ }^{6}$ Department of Medical Oncology, Dana-Farber Cancer Institute, Harvard Medical School, Boston, MA 02115, USA

Email: Pierre R Bushel* - bushel@niehs.nih.gov; Nicholas A Heard - n.heard@imperial.ac.uk; Roee Gutman - rgutman@fas.harvard.edu; Liwen Liu - liuliw@niehs.nih.gov; Shyamal D Peddada - peddada@niehs.nih.gov;

Saumyadipta Pyne* - Saumyadipta_Pyne@DFCI.HARVARD.EDU

* Corresponding authors †Equal contributors

Published: 16 September 2009

BMC Systems Biology 2009, 3:93 doi:10.1186/1752-0509-3-93
Received: 25 March 2009

Accepted: 16 September 2009

This article is available from: http://www.biomedcentral.com/l752-0509/3/93

(C) 2009 Bushel et al; licensee BioMed Central Ltd.

This is an Open Access article distributed under the terms of the Creative Commons Attribution License (http://creativecommons.org/licenses/by/2.0), which permits unrestricted use, distribution, and reproduction in any medium, provided the original work is properly cited.

\begin{abstract}
Background: Fission yeast Schizosaccharomyces pombe and budding yeast Saccharomyces cerevisiae are among the original model organisms in the study of the cell-division cycle. Unlike budding yeast, no large-scale regulatory network has been constructed for fission yeast. It has only been partially characterized. As a result, important regulatory cascades in budding yeast have no known or complete counterpart in fission yeast.

Results: By integrating genome-wide data from multiple time course cell cycle microarray experiments we reconstructed a gene regulatory network. Based on the network, we discovered in addition to previously known regulatory hubs in $M$ phase, a new putative regulatory hub in the form of the HMG box transcription factor SPBC19G7.04. Further, we inferred periodic activities of several less known transcription factors over the course of the cell cycle, identified over 500 putative regulatory targets and detected many new phase-specific and conserved cis-regulatory motifs. In particular, we show that SPBCI $9 G 7.04$ has highly significant periodic activity that peaks in early $M$ phase, which is coordinated with the late $G 2$ activity of the forkhead transcription factor $f k h 2$. Finally, using an enhanced Bayesian algorithm to co-cluster the expression data, we obtained 3 I clusters of co-regulated genes I) which constitute regulatory modules from different phases of the cell cycle, 2) whose phase order is coherent across the 10 time course experiments, and 3) which lead to identification of phase-specific control elements at both the transcriptional and posttranscriptional levels in S. pombe. In particular, the ribosome biogenesis clusters expressed in G2 phase reveal new, highly conserved RNA motifs.

Conclusion: Using a systems-level analysis of the phase-specific nature of the $S$. pombe cell cycle gene regulation, we have provided new testable evidence for post-transcriptional regulation in the G2 phase of the fission yeast cell cycle. Based on this comprehensive gene regulatory network, we demonstrated how one can generate and investigate plausible hypotheses on fission yeast cell cycle regulation which can potentially be explored experimentally.
\end{abstract}




\section{Background}

Fission yeast Schizosaccharomyces pombe and budding yeast Saccharomyces cerevisiae are among the original model organisms in the study of the cell-division cycle [1]. In particular, our understanding of the cell cycle of S. cerevisiae was greatly enhanced over the last decade owing to several genome-wide expression studies [2]. Based on such high-throughput studies, detailed regulatory networks for budding yeast were reconstructed on genomewide scale and complexity, e.g., $[3,4]$. Yet, unlike S. cerevisiae, no comprehensive cell cycle regulatory network is known for $S$. pombe. It has only been partially characterized [2]. As a result, important regulatory cascades in budding yeast have no known or complete counterpart in fission yeast.

Past comparisons of networks, which revealed both conserved and divergent control elements for similar modules across different yeasts species [5], highlighted the importance for constructing a large-scale regulatory network for fission yeast. Recently, three independent microarray studies have generated genome-wide time course gene expression data for the cell cycle of S. pombe [6-8] making it currently the organism with the largest cell cycle transcriptome. A subsequent meta-analysis [9] of ten experiments from the three studies was a first step towards aligning the data sets but no major attempt to reconstruct a $S$. pombe regulatory network has been made. Using one of the gene expression time course studies of the $S$. pombe cell cycle, Nachman and Regev [10] used a Biochemical Regulatory Network Inference (BRNI) method to identify transcriptional- and motif-based modules comprising some of the known and novel regulatory networks that control the fission yeast cell cycle. However, the limited gene expression data set representing a single form of cell cycle synchronization (elutriation), the noise inherent in the small data set and phase-specific differences between genes and transcription factors (TFs) all pose real challenges to the discovery of a comprehensive and reliable regulatory network.

In this study, we reconstructed a global gene regulatory network along with a comprehensive parts-list of co-regulated genes and significant regulators to allow systemlevel modularization of the interconnected processes involved in the $S$. pombe cell cycle. We adopted two algorithmic strategies for constructing the parts-list: 1) using the estimates of time period and phase angles from a nonlinear model, we computed phase-specific time-lagged correlations between TF-gene pairs to infer the activities of a large set of regulators and 2) partitioning a large pool of genes into clusters that are not only co-expressed in many of the ten time course experiments but are also co-regulated in the ten TF deletion and over expression experiments. These two workflows converged to produce a phase-specific network of regulatory modules. Finally we dissected the network to identify cis-elements that may indicate putative mechanisms for phase-specific transcriptional and post-transcriptional regulation of the fission yeast cell cycle.

For the researcher, the modularization of the $S$. pombe cell cycle by our gene and module networks allows for investigation of various phase-specific hypotheses on fission yeast cell cycle regulation. Due to the lack of strong evidence of transcriptional regulation in the G2 phase of the $S$. pombe cell cycle, as compared with $S$. cerevisiae, it was speculated that post-transcriptional regulation might be more active in fission yeast [2]. Indeed among the enhanced clusters of ribosome biogenesis genes that express during the G2 phase in S. pombe, we identified new, highly significant and distinctive RNA motifs in their 3' UTR sequences, thus lending support to that hypothesis. We provided evidence for transcript decay of these genes with the help of statistical analysis of their time course profiles and data from previous experiments. Thereby, we also demonstrated how our parts-list could be systematically mined for generating interesting experimentally testable hypotheses.

\section{Results \\ New modules and regulators at $M$ and $G I$ phases}

Using a curated collection of $125 \mathrm{TFs}$ in $S$. pombe with known or predicted protein domains [11], we computed phase-specific time-lagged correlation of expression profiles of all TF-gene pairs. The statistically significant (within each experiment) and consistent (across multiple experiments) correlations helped us identify a TF that is active within a phase-specific regulatory context as well as its targets therein. Specifically, a TF's activity (or TFA) is its weighted average effect as a regulator on the downstream targets at a given time point. Using Network Component Analysis (NCA) [12] we inferred strongly periodic TFAs for 36 TFs (listed in Table 1) with respect to 531 target genes (Additional file 1) during different phases of the cell cycle (Figure 1). Indeed the activity profile (Additional file 2 ) for almost every TF (in the form $\log _{10}$ (TFA) time courses) had a single, dominant periodic component as determined by the Average Periodogram method and the p-value from the related $g$-statistic [13] (Table 1, Figure 2). The Average Periodogram for each of the time courses plotted in Figure 2 is used to detect the presence of a dominant frequency of cell cycle oscillation. Almost every TF shows a single principal oscillation frequency in mutual agreement with the one cycle period. This is indicative of their regulation by common regulatory processes in a strongly periodic manner. While we identified most of the TFs that are GO annotated for cell cycle regulation, many new candidates were also inferred (e.g. an early $M$ phase HMG box TF SPBC19G7.04). 
Table I: Details about the 36 transcription factors with significant inferred activities.

\begin{tabular}{|c|c|c|c|}
\hline Cluster \# & TF coding gene & Periodic Activity P-value & Protein domain \\
\hline & Prrl & $5.70 \mathrm{E}-15$ & HSF-type DNA-binding \\
\hline 26 & SPACI9BI2.IIC & I.77E-I5 & Zinc finger, $\mathrm{C} 2 \mathrm{H} 2$ type \\
\hline 22 & Tbfl & $2.27 \mathrm{E}-06$ & Myb-like DNA-binding domain \\
\hline 7 & SPBC28F2.1I & $8.20 \mathrm{E}-07$ & HMG (high mobility group) box \\
\hline 21 & SPAC57A10.09c & $2.86 \mathrm{E}-12$ & HMG (high mobility group) box \\
\hline 12 & Pcrl* & $3.83 \mathrm{E}-26$ & Basic region leucine zipper/bZIP \\
\hline 17 & Gafl & $3.91 \mathrm{E}-23$ & GATA zinc finger \\
\hline \multirow[t]{3}{*}{22} & Orc4 & $1.85 \mathrm{E}-25$ & HMG-I and HMG-Y, DNA-binding/AT-hook \\
\hline & SPACIOF6.08c & $2.66 \mathrm{E}-06$ & HMG (high mobility group) box \\
\hline & SPBC83.17 & I.75E-03 & Helix-turn-helix \\
\hline \multirow[t]{2}{*}{14} & SPCC320.03 & $1.96 \mathrm{E}-04$ & Fungal $\mathrm{Zn}(2)-\mathrm{Cys}(6)$ binuclear cluster domain \\
\hline & SPAPBIAII.04c & I.35E-05 & Fungal $\mathrm{Zn}(2)-\mathrm{Cys}(6)$ binuclear cluster domain \\
\hline 4 & Bdpl & 4.27E-16 & Myb-like DNA-binding domain \\
\hline 30 & Ace2* & $3.23 \mathrm{E}-16$ & Zinc finger, $\mathrm{C} 2 \mathrm{H} 2$ type \\
\hline 11 & Cnp3 & $2.04 \mathrm{E}-14$ & HMG-I and HMG-Y, DNA-binding/AT-hook \\
\hline 31 & SPBCI9G7.04 & $3.06 \mathrm{E}-10$ & HMG (high mobility group) box \\
\hline \multirow[t]{2}{*}{31} & Fkh2* & 7.76E-09 & Fork head domain \\
\hline & Stell & 4.97E-10 & HMG (high mobility group) box \\
\hline 23 & $\mathrm{Phxl}$ & I.04E-08 & Homeobox domain \\
\hline 7 & $\operatorname{Rep} 2^{*}$ & $1.96 \mathrm{E}-05$ & Zinc finger, $\mathrm{C} 2 \mathrm{H} 2$ type \\
\hline \multirow[t]{2}{*}{22} & SPBC530.05 & $6.90 \mathrm{E}-04$ & Fungal $\mathrm{Zn}(2)-\mathrm{Cys}(6)$ binuclear cluster domain \\
\hline & SPBCI5D4.02* & $1.82 \mathrm{E}-03$ & Fungal $\mathrm{Zn}(2)-\mathrm{Cys}(6)$ binuclear cluster domain \\
\hline 21 & Php5 & 4.IIE-I4 & Histone-like TF (CBF/NF-Y) \\
\hline \multirow[t]{2}{*}{12} & Atfl* & $9.07 \mathrm{E}-17$ & Basic region leucine zipper/bZIP \\
\hline & SPBC2IBI0.13c & $3.34 \mathrm{E}-07$ & Homeobox domain \\
\hline 31 & Ams2* & $\mathrm{I} .4 \mathrm{IE}-04$ & GATA zinc finger \\
\hline 5 & Mug 152 & $2.08 \mathrm{E}-09$ & Myb-like DNA-binding domain \\
\hline 22 & SPACIBI.0I & $5.28 \mathrm{E}-06$ & Zinc finger, $\mathrm{C} 2 \mathrm{H} 2$ type \\
\hline
\end{tabular}


Table I: Details about the 36 transcription factors with significant inferred activities. (Continued)

\begin{tabular}{clll}
\hline II & SPBCI683.I3c & I.I7E-13 & Fungal Zn(2)-Cys(6) binuclear cluster domain \\
\hline 16 & Hsrl & $1.62 \mathrm{E}-08$ & Zinc finger, C2H2 type \\
\hline 9 & SPBC19C7.10 & $1.55 \mathrm{E}-04$ & APSES domain \\
\hline 24 & SfC2 & $3.29 \mathrm{E}-07$ & Myb-like DNA-binding domain \\
\hline 12 & Rsv2 & $4.47 \mathrm{E}-05$ & Zinc finger, C2H2 type \\
\hline 26 & SPCC550.15c & $6.46 \mathrm{E}-03$ & Zinc finger, C2H2 type \\
\hline & SPAC3C7.04 & $3.60 \mathrm{E}-08$ & Zinc finger, C2H2 type \\
\hline
\end{tabular}

*Denotes a TF that is annotated as cell cycle relevant in Gene Ontology (GO).

Based on the regulatory matrix of the $36 \mathrm{TFs}$ and their downstream targets in multiple experiments, we reconstructed a gene regulatory network (Additional file 3), which could be mined for inferring phase-specific modules and sub-networks. For instance, a majority of the 36 TFs were found to regulate one or more modules in the $\mathrm{M}$ and G1 phases (Figure 3A and see Additional file 4). In

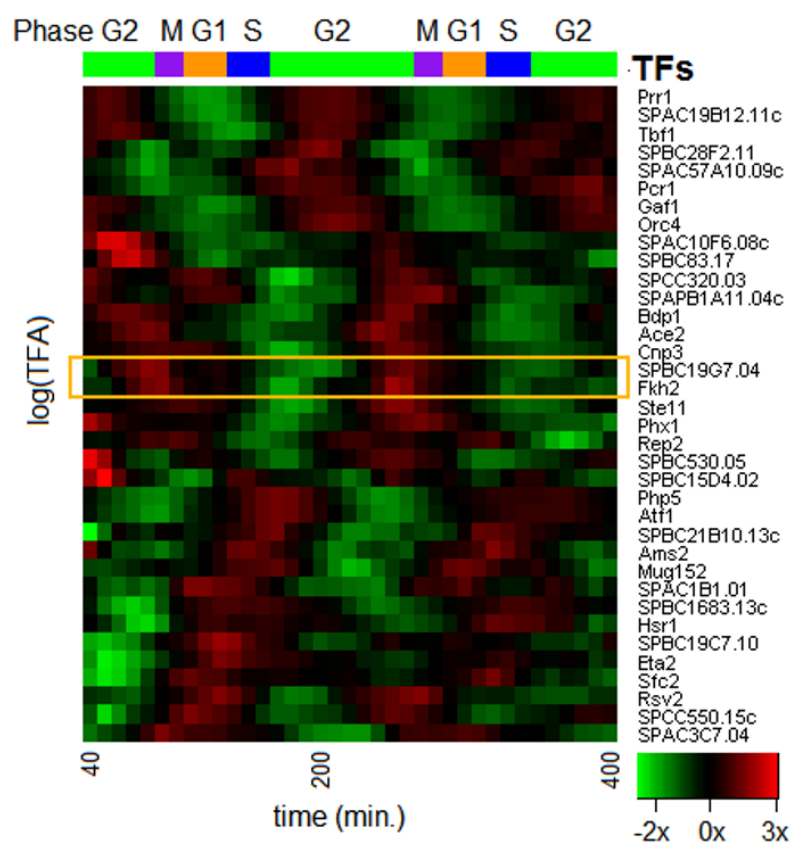

Figure I

Transcription factor activities over the course of cell cycle. Inferred activities of the 36 selected TFs, clustered with respect to similarity of activities based on Peng Cdc25. The cell cycle phases are indicated. TFs $f k h 2$ and SPBC 19G7.04 are highlighted with a rectangle. addition, specific gene-level regulatory links may be studied by dissecting the global network. For instance, a subnetwork of early $M$ phase clusters (Figure $3 B$ ) revealed a new regulatory hub in the form of the HMG box TF SPBC19G7.04 (denoted by an arrow in Figure 3B), besides such well-known hubs as the key TF ace 2 and the polo kinase plo1.

\section{Clusters of co-regulated genes lead to new phase-specific control elements}

As a basis of our large-scale regulatory network, we sought out to construct a parts-list (as defined in [14]) of statistically significant cell cycle components such as a large number of co-regulated gene clusters and their putative regulators. To increase statistical power for detection of new or subtle modes of regulation, we enhanced a Bayesian algorithm [15] with new strategies to co-cluster different types of experiments and identify co-regulated genes. The revised algorithm accommodates heterogeneous data types by modeling (individually) each of the ten cell cycle time course experiments and the ten TF deletion or overexpression experiments with suitable basis functions. With the help of effective priors to model the periodically expressed profiles apart from the monotonic trends, the algorithm produced an optimal clustering of 2000 fission yeast genes into 31 disjoint clusters (Figure 4, and Additional file 5 Figure S1). Details regarding the 31 clusters of co-expressed genes are summarized in Table 2. A complete list of the 2000 genes categorized by the cluster numbers is in Additional file 6. We also determined the regulatory signature of every cluster (Additional file 5 Figure S2). An example of a periodic cluster containing 49 genes expressed in $\mathrm{M}$ phase is shown in Figure 5.

The co-regulated genes within the clusters were characterized and validated. Gene Ontology (GO) analysis 

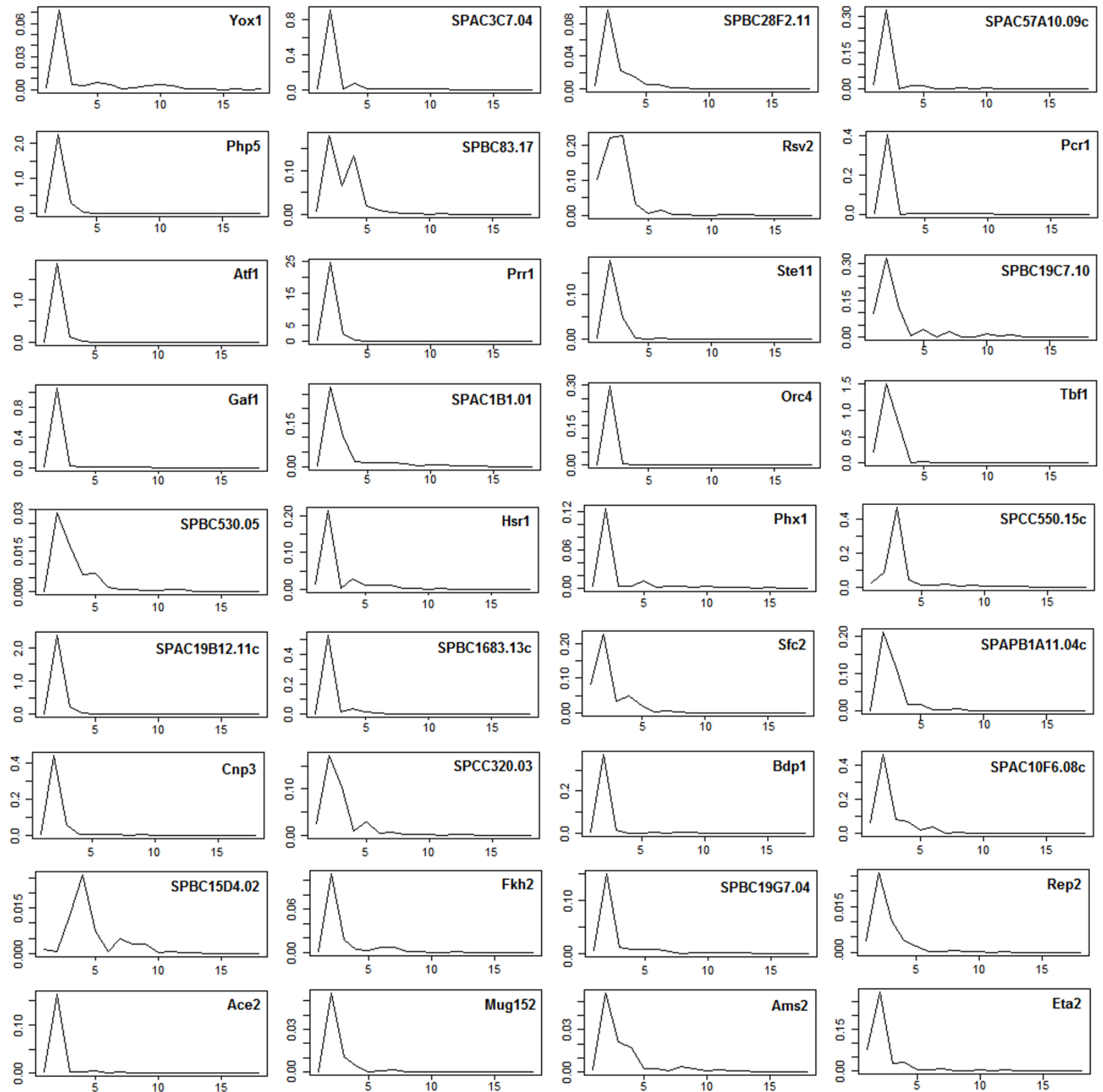

Figure 2

Statistical significance of the transcription factor activities. Most of the strongly periodic activity profiles $\left(\log _{10}(\right.$ TFA $\left.)\right)$ of the 36 selected TFs have a single dominant frequency of oscillation. The $x$-axis marks the different Fourier frequencies and the $y$-axis represents the Average Periodogram [13]. Clearly the dominant Fourier frequency, marked by a spike, is very prominent in every TF, and is indicative of its strongly periodic profile. Further, the similarity among the locations of the spikes across all 36 TFs shows their regulation by common cell cycle processes. Also see Table I for the related $p$-values that measure the periodicity of each profile.

revealed that many of the genes within the clusters were represented by known functional categories from different stages of the cell cycle (Table 2). Testing of circular uniformity of peak phase angles of genes in each cluster determined that 29 out of 31 clusters were cell cycle phase-specific. Circular-circular Regression (CCR) [16] showed that during cell cycle progression, the phase ordering of the 31 clusters exhibited significant $(\mathrm{P}=$ 
A)

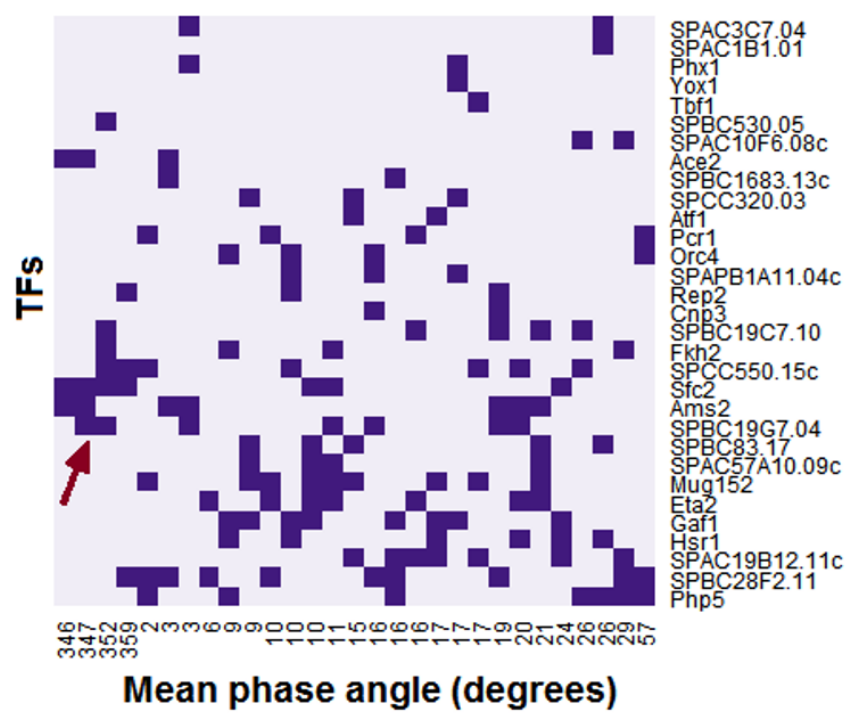

B)

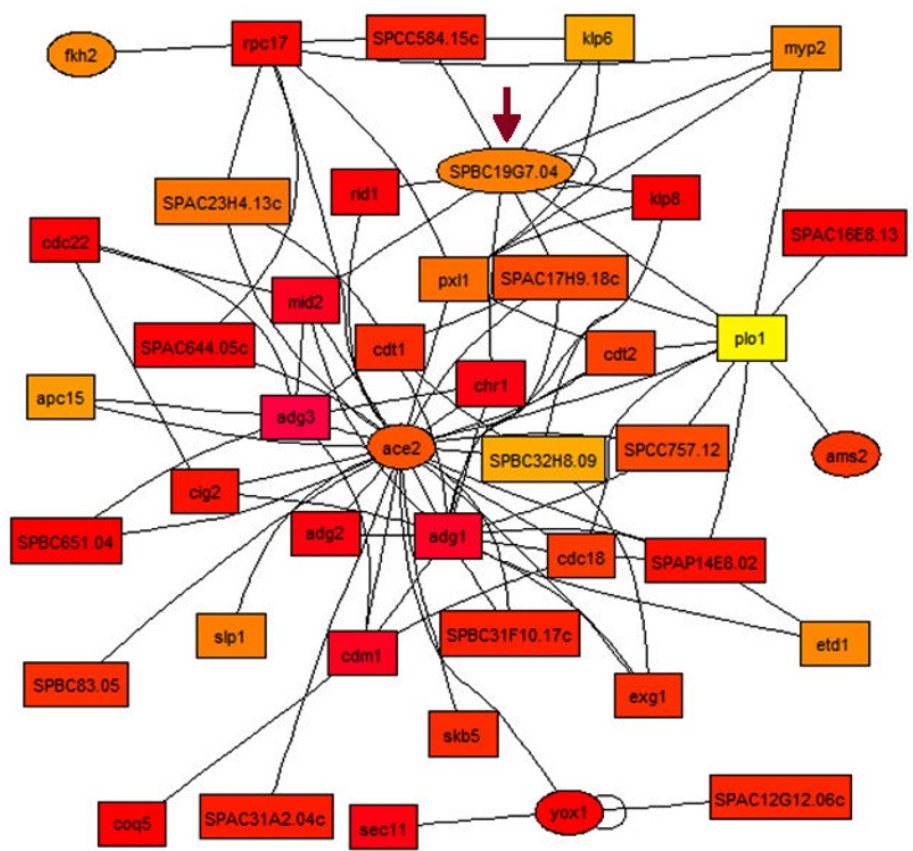

Figure 3

Dissecting $M$ and $G$ I phase subnetworks. A) A network of $M$ and $G I$ phase gene modules are shown, sorted by mean phase. If a TF is found to be a regulator for a module then it is depicted with a purple square. Potential regulation of $M$ phase modules by SPBC19G7.04 is pointed out with an arrow. B) Early M phase gene regulatory network in which TFs are shown in ellipses, and the rest of the genes in boxes. The colors of the nodes are according to their peak phase, where more reddish colors represent phases that are later in M and thereafter, while more orange and yellow hues depict earlier (late G2 and G2/ M) phases. The regulatory hub for the early M phase TF SPBC19G7.04 is marked with an arrow. 
Table 2: Details about the 3 I clusters of co-expressed genes.

\begin{tabular}{|c|c|c|c|c|c|}
\hline Cluster \# & $\begin{array}{c}\text { Siz } \\
\text { e }\end{array}$ & Mean phase (degrees) & $\begin{array}{l}\text { p-value for phase } \\
\text { uniformity }\end{array}$ & Significant motif & $\begin{array}{l}\text { Dominant Gene Ontology } \\
\text { category }\end{array}$ \\
\hline 9 & 76 & 6 & $4.54 \mathrm{E}-0 \mathrm{I}$ & & transmembrane transporter activity \\
\hline 5 & 52 & 17 & $7.81 \mathrm{E}-08$ & & $\begin{array}{l}\text { cellular metabolic process, cellular } \\
\text { component organization and } \\
\text { biogenesis }\end{array}$ \\
\hline 14 & 42 & 42 & $6.4 \mathrm{IE}-04$ & Mcbl & $\begin{array}{l}\text { nucleotide binding, substrate- } \\
\text { specific transporter activity }\end{array}$ \\
\hline 21 & 80 & 49 & 2.07E-17 & G.TTGT [TG] [AG] & oxidoreductase activity \\
\hline 29 & 9 & 53 & $6.84 \mathrm{E}-12$ & Histone CACCACC & histones \\
\hline 15 & 41 & 55 & $1.49 \mathrm{E}-18$ & GTTGGC [AT]GT & ion binding \\
\hline 10 & 12 & 95 & $3.54 \mathrm{E}-02$ & & $\begin{array}{l}\text { cellular metabolic process, protein } \\
\text { binding, stress response }\end{array}$ \\
\hline 12 & 96 & 102 & $3.52 \mathrm{E}-04$ & & transmembrane transporter activity \\
\hline 20 & 78 & 103 & I.27E-07 & CAAGTT & $\begin{array}{l}\text { transport, establishment of } \\
\text { localization }\end{array}$ \\
\hline 18 & 34 & 108 & $1.89 \mathrm{E}-16$ & & $\begin{array}{l}\text { cellular metabolic process, nitrogen } \\
\text { compound metabolic process }\end{array}$ \\
\hline 17 & 61 & 112 & $4.52 \mathrm{E}-12$ & & $\begin{array}{l}\text { cellular metabolic process, cofactor } \\
\text { binding }\end{array}$ \\
\hline 16 & 49 & 135 & I.57E-25 & GTT.GCT & $\begin{array}{l}\text { nitrogen compound metabolic } \\
\text { process }\end{array}$ \\
\hline 27 & 45 & 139 & $1.76 \mathrm{E}-02$ & & transmembrane transporter activity \\
\hline 28 & 8 & 150 & $8.00 \mathrm{E}-07$ & & \\
\hline 19 & 24 & 174 & $9.65 \mathrm{E}-15$ & $\begin{array}{l}\text { GTGACTG [CT]T } \\
\text { TAGGGTAGGG }\end{array}$ & $\begin{array}{l}\text { cellular metabolic process, } \\
\text { structural constituent of ribosome }\end{array}$ \\
\hline 22 & 47 & 175 & $5.38 \mathrm{E}-02$ & CGTTAGTTTT & regulation of metabolic process \\
\hline 23 & 118 & 175 & $1.03 \mathrm{E}-06$ & & \\
\hline 26 & 83 & 188 & $1.90 \mathrm{E}-39$ & AGTTTG & $\begin{array}{l}\text { cellular component organization and } \\
\text { biogenesis }\end{array}$ \\
\hline 11 & 43 & 194 & $9.52 \mathrm{E}-04$ & GTCGGTTTCC & transmembrane transporter activity \\
\hline 24 & 103 & 195 & $3.52 \mathrm{E}-18$ & & $\begin{array}{l}\text { cellular metabolic process, ion } \\
\text { binding }\end{array}$ \\
\hline 25 & 59 & 211 & 4.09E-02 & [GT]TAAACA & ribosome biogenesis and assembly \\
\hline 3 & 70 & 255 & $1.06 \mathrm{E}-07$ & TGTTTAC & cell cycle, chromosome segregation \\
\hline 13 & 60 & 258 & $9.74 \mathrm{E}-05$ & & cell cycle \\
\hline
\end{tabular}


Table 2: Details about the $3 \mathrm{I}$ clusters of co-expressed genes. (Continued)

\begin{tabular}{|c|c|c|c|c|c|}
\hline 1 & 155 & 259 & $2.21 \mathrm{E}-1 \mathrm{I}$ & FKH & $\begin{array}{l}\text { cell cycle, stress response, cellular } \\
\text { metabolic process, protein binding, } \\
\text { response to endogenous stimulus }\end{array}$ \\
\hline 2 & 131 & 276 & $3.34 \mathrm{E}-13$ & FKH TCTTCT & cell cycle \\
\hline 4 & 101 & 286 & I.07E-06 & FKH TGTAAGC & $\begin{array}{l}\text { cell cycle, cellular component } \\
\text { organization and biogenesis }\end{array}$ \\
\hline 8 & 41 & 328 & $1.74 \mathrm{E}-02$ & ACCATTG FKH & $\begin{array}{l}\text { primary metabolic process, ion } \\
\text { binding, regulation of biological } \\
\text { quality }\end{array}$ \\
\hline 6 & 140 & 343 & I.39E-03 & T [GC]GTG [TG]T & $\begin{array}{l}\text { cellular component organization and } \\
\text { biogenesis }\end{array}$ \\
\hline 31 & 49 & 344 & I.47E-33 & FKH & cell division, cytokinetic process \\
\hline 30 & 22 & 357 & $6.56 \mathrm{E}-05$ & Dbllo Ace2 & $\begin{array}{l}\text { cell cycle, regulation of metabolic } \\
\text { process }\end{array}$ \\
\hline 7 & 71 & 359 & $6.15 \mathrm{E}-13$ & Ace2 & cell cycle, cell communication \\
\hline
\end{tabular}

Motifs similar to known motifs are given by the name published in the literature (ACCACA McbI, CCCTTACCC Histone, TTGTTTAC FKH, CGTGTCGCGT DbII0, ACCAGCC Ace2). Newly discovered motifs are given by their consensus sequence.

0.037) coherence across the ten time course experiments. Significant $(\mathrm{P}<10-9)$ and non-redundant putative binding sites, many of which were conserved across different fission yeasts, were detected for most of the clusters (Table 2 ). Several new and interesting motifs were observed (e.g. TGTAWGC in Cluster 4) beside some that were previously known (e.g. the forkhead FKH motif TTGTTTAC).

\section{Post-transcriptional regulation of ribosome biogenesis genes}

Post-transcriptional regulation plays a key role in the control of gene expression in terms of processing, transport, localization, quality control and turnover of mRNA transcripts. Therefore, systematic identification of targets for such regulation is of fundamental importance to the investigation of multi-layered gene regulation $[14,15]$. In the present study, we identified new, highly conserved motifs in the 3' UTR sequences of 65 co-regulated genes from clusters 25 and 26 that are involved mostly in ribosome biogenesis in $S$. pombe (Figure 6A; the genes are listed in Table 3). Two single-stranded motifs U [UG]UU [CG]G and GGG [AU] in 3' UTR [17] were highly statistically significant $\left(P<10^{-47}\right.$ and $10^{-67}$ respectively) with strong positional bias within the range of the first 300 nucleotides. In the most significant occurrence of the resulting RNA motif (as in SPBC26H8.08c), they appeared overlapped as UUCUUCGGGUUUUAA with a small loop structure, denoted by (see Figure 6A). See Additional file 7 for associated likelihood scores. Dominant GO categories of biological process and cellular component for the proteins encoded by the genes containing the motifs include RNA process- ing $\left(P<10^{-39}\right)$ and nucleus-nucleolus $\left(P<10^{-52}\right)$ respectively (the gene products are described in Table 3 ).

The transcriptome and the proteome have long been compared to gain insights on RNA turnover [18-20]. Thus, to explore the present hypothesis, we analyzed comparative transcriptomic and proteomic measurement data of $\mathrm{S}$. pombe gene expression from a previous high-throughput study [21]. Genes with low correlation between their transcriptomic and proteomic levels could be substantially regulated by post-transcriptional mechanisms [22]. Both types of measurements were available in the above data for 22 of the 65 genes that had the motifs, and for 30 of the remaining genes (in clusters 25 and 26) that did not. We first computed the percentile scores separately for each measurement to be able to compare them on the same scale (Figure 6B). As shown in the lower left (blue) quadrant, the few genes with the motifs and low transcript levels are correlated with their protein product expression. Given this data set, perhaps it may be reasonable to assume that the mRNA abundance in the cells is sufficient for carrying out various biological processes during the cell cycle. However, the correlation between the transcriptomic and proteomic levels for the genes with high expression and containing the motifs was lower $(P=0.07$ not significant for H0: $\rho=0$ at level 0.05) than those without them (significant correlation with $\mathrm{P}=0.004$ ). Indeed most of the genes carrying the motifs and having aboveaverage transcript level (percentile score $>0.5$ ) have a steadily low protein level (percentile score $<0.5$; see red quadrant in Figure 6B) potentially indicative of transcript 


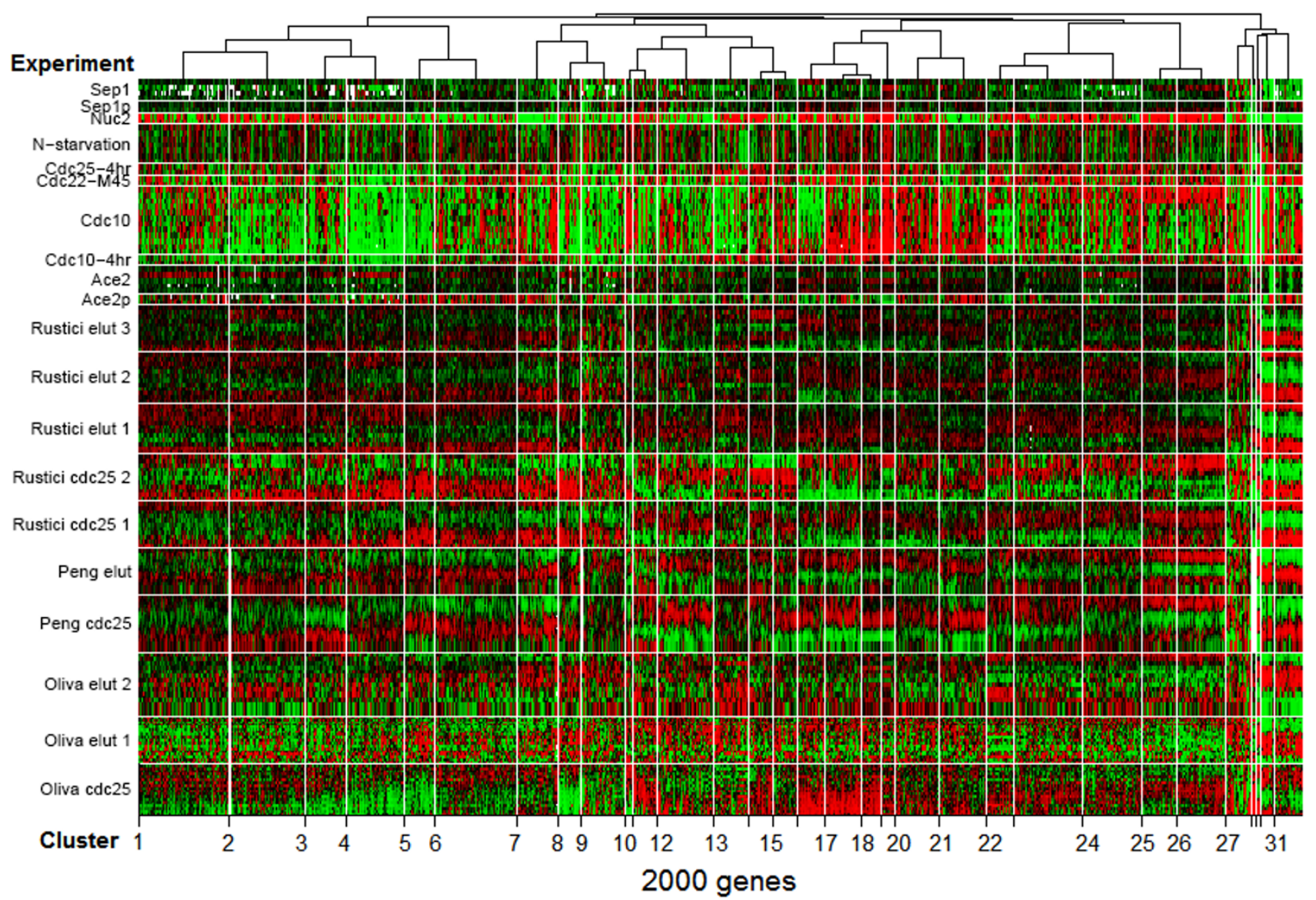

\section{Figure 4}

Co-expressed gene clusters with regulatory signatures. Data from ten cell cycle time course experiments were integrated with ten regulatory TF knockout and overexpression experiments to produce 3 I clusters. Columns are clusters of 2000 fission yeast genes and each row an experiment. One cycle long time courses are shown depicting the cyclic (high-and-low) expression for every cluster. (Color code: red-high, green-low, white-missing expression.)

decay or short half-life. Conversely, the majority of genes without the motifs had a protein level consistent with their transcript level (blue quadrants). Similarly, high correlation $(\rho=0.66)$ was observed for cell cycle genes in general highlighting further the discrepancy between the transcriptomic and proteomic levels of many of the genes that contained the motifs [21]. Given the generally high values of AUG Context Adaptation Index (mean $=0.56$, s.d. $=0.15)$ and ribosome occupancy (mean $=81 \%$, s.d. $=$ $4.3 \%$ ) of these genes [23], the discrepancy may be more likely due to post-transcriptional regulation than to lack of translational efficiency.

We believe that the shapes of the time-course profiles of genes containing the RNA motifs can provide useful information regarding the pattern of their decay in G2-phase. We used standard statistical measures such as skewness and kurtosis of a time course [24] to describe the decay characteristics. The skew and excess kurtosis statistics measure respectively, the asymmetry and the peakedness of a profile that could shed light on the temporal pattern of its decay. For instance, while a left skewed profile (given by a negative value of skew) may represent an early peaking gene, a heavy right-tailed profile (given by a positive excess kurtosis) denotes slow decay rate. Therefore, we first computed the skew of each of the above 65 profiles restricted to the first full duration of the G2 phase, and then the kurtosis by focusing on the right tail (see Table 3). We noted that most of the genes are expressed in early- to mid-G2 phase, i.e. with left or negative skew, as is consistent with the ribosome biogenesis expression previously observed [6]. Clearly, most profiles had a sharp decline as G2 progresses, which are captured by the negative excess kurtosis of their right tails.

\section{Discussion}

In the study of the systems biology of a unicellular organism such as fission yeast, the importance of the intercon- 

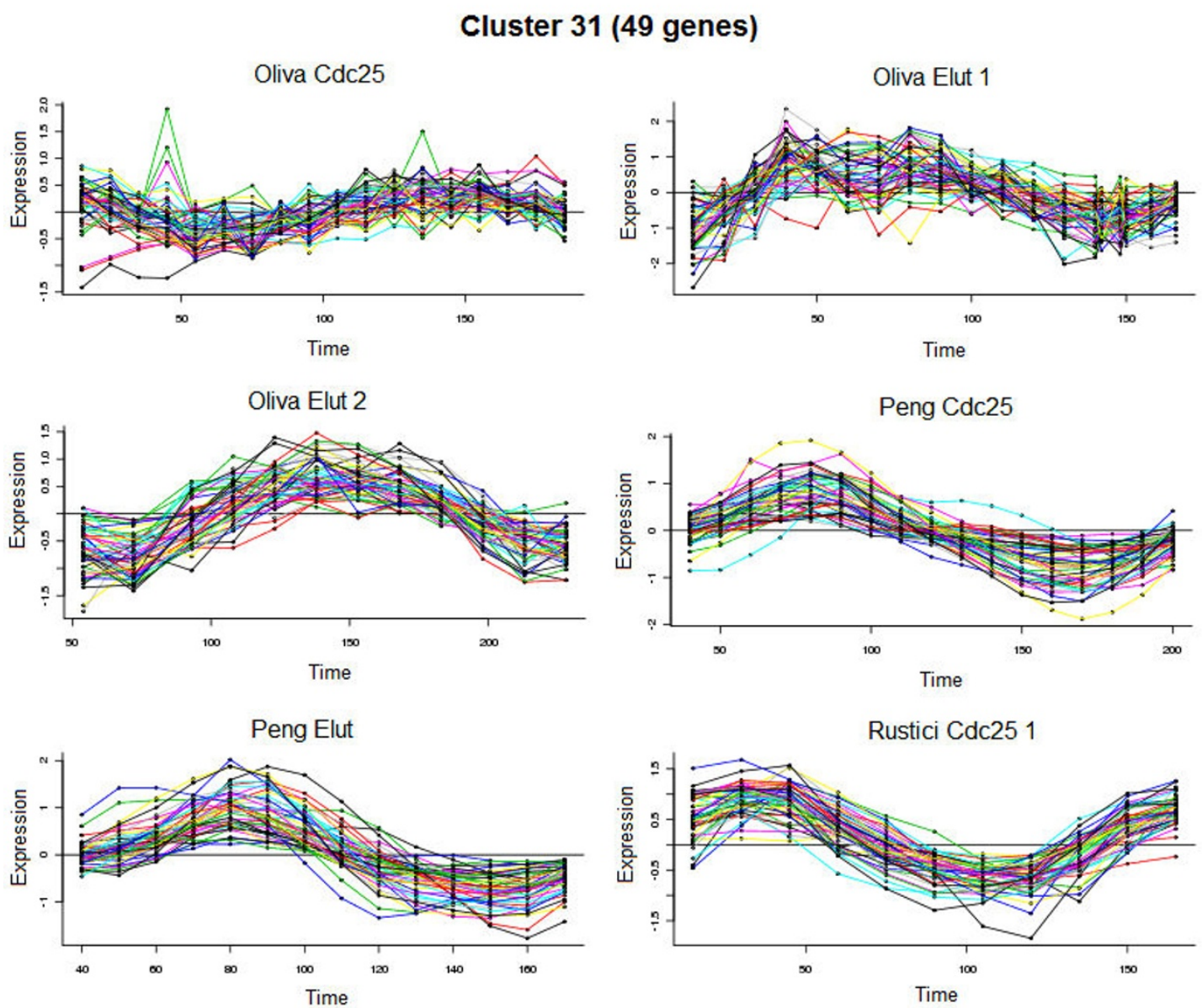

Rustici Cdc25 2
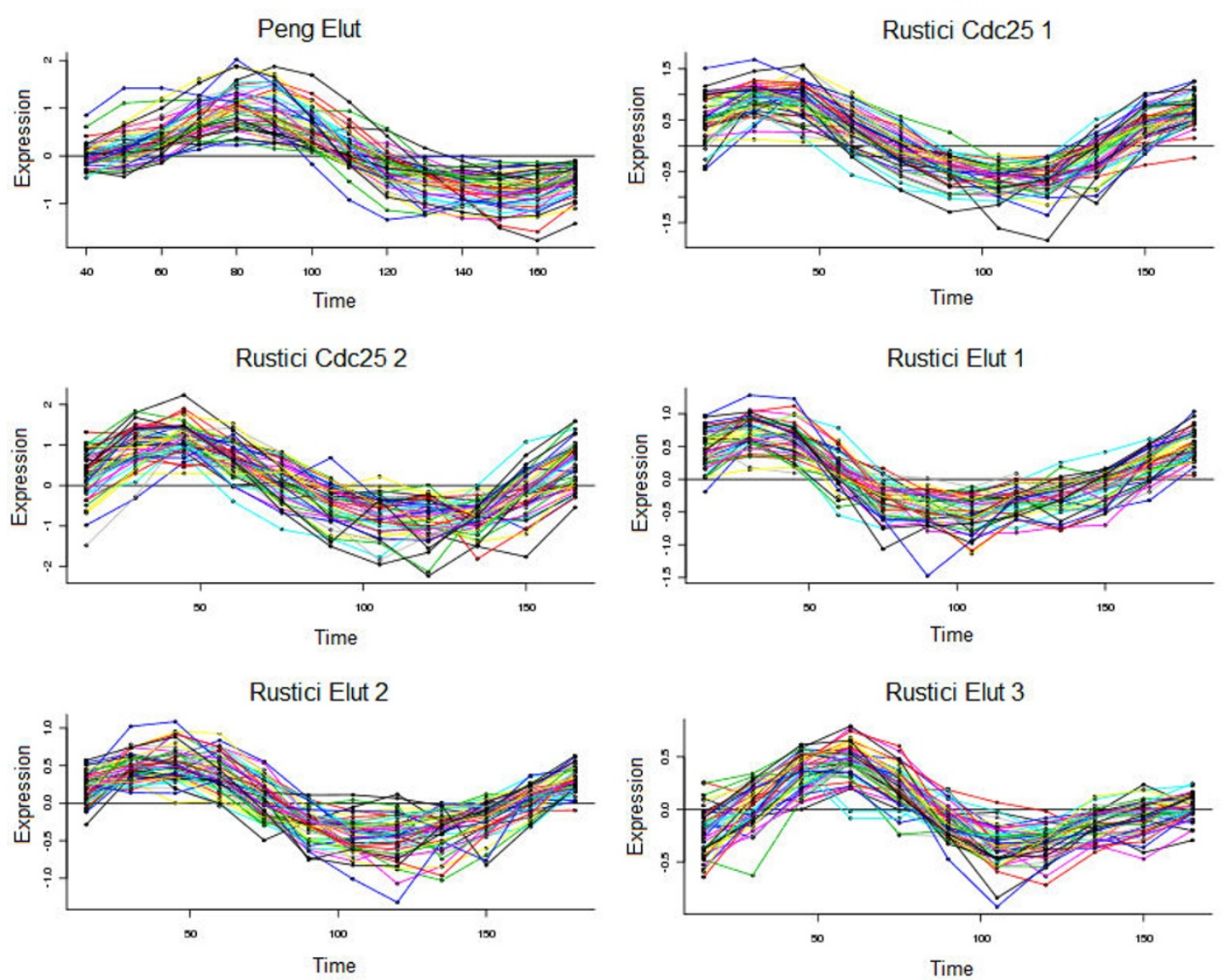

Figure 5

A representative co-expressed gene cluster identified with the revised co-clustering algorithm. Cell cycle time courses of 49 genes belonging to cluster 31 in mid-M phase are shown. 
Table 3: Genes from clusters 25 and 26 carrying the 3'UTR RNA motifs (the list is ordered exactly as depicted in Figure 6A).

\begin{tabular}{|c|c|c|c|c|c|}
\hline Gene & Cluster & Gene Product & P-value of expression & Skew & Kurtosis \\
\hline SPACI 565.05 & 25 & Ribosomal protein L29 & $2.90 \mathrm{E}-03$ & -0.348 & -1.555 \\
\hline SPACI6E8.06c & 25 & RNA-binding protein Nop 12 & $3.89 E-04$ & -0.524 & -0.532 \\
\hline SPACI8BII.06 & 25 & U3 snoRNP-associated protein Lcp5 & I. $18 \mathrm{E}-05$ & 0.315 & -0.893 \\
\hline SPAC222.06 & 25 & nuclear HMG-like acidic protein Mak 16 & $2.29 \mathrm{E}-05$ & 0.827 & -0.185 \\
\hline SPAC22E I $2.13 \mathrm{C}$ & 25 & $60 S$ ribosomal protein L24-3 (L30) & 7.69E-05 & -0.314 & -1.715 \\
\hline SPAC22EI 2.18 & 25 & Uncharacterized protein C22EI2.18 & $2.99 \mathrm{E}-03$ & -0.256 & -1.451 \\
\hline SPAC22F3.08c & 25 & ATP-dependent RNA helicase RokI & $2.26 \mathrm{E}-02$ & 0.747 & 0.049 \\
\hline SPAC22F8.09 & 25 & rRNA processing protein Rrpl6 & $3.16 \mathrm{E}-04$ & 0.509 & 0.150 \\
\hline SPAC26A3.06 & 25 & methyltransferase & 7.17E-03 & 0.237 & -1.379 \\
\hline SPAC2EIP5.05 & 25 & U3 snoRNP-associated protein Rrp9 & $9.06 \mathrm{E}-04$ & -0.554 & -1.587 \\
\hline SPAC3G9.15c & 25 & rRNA processing protein Fcf2 & I.15E-02 & -0.064 & -1.423 \\
\hline SPAC4F8.04 & 25 & Brix domain protein Rpfl & $2.64 \mathrm{E}-03$ & 0.028 & -0.944 \\
\hline SPAC56F8.09 & 25 & rRNA methyltransferase Rrp8 & $1.91 \mathrm{E}-04$ & -0.299 & -1.422 \\
\hline SPAC57A7.06 & 25 & U3 snoRNP protein Utp I4 & $6.01 \mathrm{E}-05$ & 0.174 & -1.597 \\
\hline SPAC $664.08 \mathrm{c}$ & 25 & traub family protein & I.52E-07 & -0.239 & -1.455 \\
\hline SPAC683.02c & 25 & zf-CCHC type zinc finger protein & I. $10 \mathrm{E}-06$ & 0.686 & 0.119 \\
\hline SPAC823.08c & 25 & ATP-dependent RNA helicase Rrp3 & I.5IE-03 & -0.050 & -1.231 \\
\hline SPAC890.05 & 25 & ribosome biogenesis protein & I.17E-05 & 0.482 & -0.181 \\
\hline SPAC926.08c & 25 & Brix domain protein Rpf2 & $6.14 \mathrm{E}-08$ & -0.114 & -1.409 \\
\hline SPBCIIGII.03 & 25 & ribosome assembly protein & $6.15 \mathrm{E}-04$ & -0.241 & -1.781 \\
\hline SPBCI3GI.09 & 25 & bystin-family protein & I.04E-07 & 0.170 & -0.725 \\
\hline SPBCI4C8.14c & 25 & DNA polymerase phi & $6.61 \mathrm{E}-02$ & -0.290 & -1.667 \\
\hline SPBCI604.09c & 25 & exoribonuclease Rex4 & $5.43 \mathrm{E}-04$ & 0.605 & 0.702 \\
\hline SPBCI7II.04 & 25 & methylenetetrahydrofolate reductase & 6.7IE-0I & 0.397 & -1.564 \\
\hline SPBCI7I8.03 & 25 & DNA-directed RNA polymerase I complex subunit Ker I & $7.68 \mathrm{E}-06$ & -0.048 & -1.673 \\
\hline SPBCI734.0Ic & 25 & pre-rRNA processing protein Esfl & $4.48 \mathrm{E}-02$ & -0.095 & -1.293 \\
\hline SPBCI9F5.05c & 25 & pescadillo-family BRCT domain protein & $4.23 \mathrm{E}-05$ & -0.448 & -1.747 \\
\hline SPBC215.06c & 25 & human LYHRT homolog & $1.53 \mathrm{E}-05$ & 0.088 & -1.519 \\
\hline SPBC24C6.02 & 25 & ATP-dependent RNA helicase Spb4 & $7.5 \mathrm{IE}-05$ & 0.292 & -0.529 \\
\hline $\mathrm{SPBC} 26 \mathrm{H} 8.08 \mathrm{c}$ & 25 & GTPase Grn I & $3.79 \mathrm{E}-05$ & -0.450 & -1.602 \\
\hline
\end{tabular}


Table 3: Genes from clusters 25 and 26 carrying the 3'UTR RNA motifs (the list is ordered exactly as depicted in Figure 6A). (Continued)

\begin{tabular}{|c|c|c|c|c|c|}
\hline SPBC28EI2.05 & 25 & U3 snoRNP-associated protein Esf2 & $2.75 \mathrm{E}-0 \mathrm{I}$ & 0.511 & -0.565 \\
\hline SPBC2DI0.19c & 25 & pre-60S shuttlingfactor & I.23E-04 & -0.268 & -1.346 \\
\hline SPBC2G5.03 & 25 & cytosolic thiouridylase subunit Ctul & $6.83 \mathrm{E}-05$ & 0.770 & -0.344 \\
\hline SPBC3IEI.06 & 25 & GTP binding protein Bms I & $5.75 \mathrm{E}-04$ & 0.206 & -0.677 \\
\hline SPBC336.02 & 25 & I8S rRNA dimethylase & 2.47E-03 & & \\
\hline SPBC409.15 & 25 & rRNA processing protein Tsr2 & $2.5 \mathrm{IE}-02$ & -0.071 & -1.343 \\
\hline SPBP8B7.10c & 25 & U3 snoRNP-associated protein Utp I 6 & $5.91 \mathrm{E}-02$ & -0.215 & -1.578 \\
\hline SPCCI8.12c & 25 & rRNA processing protein & $4.43 \mathrm{E}-03$ & 0.305 & -1.143 \\
\hline SPCC24B 10.18 & 25 & human Leydig cell tumor $10 \mathrm{kDa}$ protein homolog & $3.23 \mathrm{E}-04$ & 0.539 & -0.725 \\
\hline SPCC550.15c & 25 & ribosome biogenesis protein & I.70E-02 & -0.495 & -1.676 \\
\hline SPCPIEII.II & 25 & Puf family RNA-binding protein & $3.26 \mathrm{E}-04$ & -0.565 & -1.238 \\
\hline SPACI527.03 & 26 & RNA-binding protein & 2.14E-04 & -0.239 & -1.786 \\
\hline SPACI5AI0.04c & 26 & EF-I alpha binding zinc finger protein ZprI & $\mathrm{I} .02 \mathrm{E}-04$ & -0.336 & -1.436 \\
\hline SPACI687.II & 26 & rRNA methyltransferase SpbI & $1.06 \mathrm{E}-04$ & 0.275 & -1.080 \\
\hline SPAC23H4.I5 & 26 & ribosome biogenesis protein Tsrl & 4.8IE-04 & -0.333 & -1.788 \\
\hline SPAC30C2.02 & 26 & deoxyhypusine hydroxylase & $3.06 \mathrm{E}-04$ & -0.347 & -1.621 \\
\hline SPAC3IA2.07c & 26 & ATP-dependent RNA helicase Dbp I0 & $5.04 \mathrm{E}-02$ & -0.138 & -1.519 \\
\hline SPAC4F8.12c & 26 & U5 snRNP complex subunit Spp42 & $6.80 \mathrm{E}-0 \mathrm{I}$ & -0.440 & $-1.72 \mid$ \\
\hline SPAC6FI2.16c & 26 & ATP-dependent RNA helicase, TRAMP complex subunit Mtr4 & $2.66 \mathrm{E}-04$ & -0.266 & -1.411 \\
\hline SPAPBIAI0.06c & 26 & ATP-dependent RNA helicase Dhrl & $1.29 \mathrm{E}-05$ & -0.048 & -1.539 \\
\hline SPBCI6E9.10c & 26 & AAA family ATPase Rix7 & $6.65 \mathrm{E}-04$ & -0.258 & -1.735 \\
\hline $\mathrm{SPBCI} 6 \mathrm{H} 5.08 \mathrm{c}$ & 26 & ribosome biogenesis ATPase, Arb family ABCF2-like & I.59E-02 & -0.044 & -1.634 \\
\hline SPBCI7DI.06 & 26 & ATP-dependent RNA helicase Dbp3 & $1.36 \mathrm{E}-06$ & & \\
\hline SPBC244.02c & 26 & U3 snoRNP-associated protein Utp6 & $2.54 \mathrm{E}-03$ & -0.368 & -1.599 \\
\hline SPBC $4 C 3.05 c$ & 26 & DNA-directed RNA polymerase I complex large subunit Nuc I & 4.79E-04 & -0.103 & -1.079 \\
\hline SPBC $4 F 6.07 c$ & 26 & ATP-dependent RNA helicase Mak5 & $2.2 \mathrm{IE}-02$ & 0.191 & -1.272 \\
\hline SPBC4F6.13c & 26 & WD repeat/BOPINT protein & I.IIE-03 & -0.526 & -1.413 \\
\hline SPBC65I.0Ic & 26 & GTP binding protein Nog $\mathrm{I}$ & 4.48E-09 & & \\
\hline SPBC776.08c & 26 & Nrap (snoRNA binding) & $5.23 \mathrm{E}-06$ & -0.424 & -1.720 \\
\hline SPBP22H7.02c & 26 & RNA-binding protein MrdI & $2.43 \mathrm{E}-06$ & -0.179 & -1.690 \\
\hline SPCCII83.07 & 26 & U3 snoRNP-associated protein Rrp5 & $9.57 \mathrm{E}-07$ & -0.142 & -1.475 \\
\hline SPCCI827.0Ic & 26 & DUFI253 family protein & $1.58 \mathrm{E}-03$ & -0.126 & -1.760 \\
\hline
\end{tabular}


Table 3: Genes from clusters 25 and 26 carrying the 3'UTR RNA motifs (the list is ordered exactly as depicted in Figure 6A). (Continued)

\begin{tabular}{lllllll}
\hline SPCC320.08 & 26 & membrane transporter & $5.16 \mathrm{E}-05$ & -0.166 & -1.538 \\
\hline SPCC330.09 & 26 & rRNA processing protein Enp2 & $9.94 \mathrm{E}-04$ & 0.128 & -0.810 \\
\hline SPCC737.08 & 26 & midasin & $2.82 \mathrm{E}-02$ & -0.309 & -1.437 \\
\hline
\end{tabular}

nected cell cycle processes cannot be over-emphasized. However, the processes could be studied both in terms of their connectedness to each other as well as their cell cycle phase-specificity. To encompass both the global and the local aspects of the underlying gene regulatory network for $S$. pombe, we took a 3-step approach. First, using genome-wide expression data from multiple experiments, we reconstructed a gene regulatory network based on 531 downstream target genes of 36 transcription factors that were identified to have strongly periodic activity during the cell cycle (Table 1, Figures 1 and 2). Second, we coupled TF mutant data from ten microarray studies with time course expression data from ten cell cycle experiments with the help of an enhanced Bayesian co-clustering algorithm. The co-regulated and phase-specific gene modules (Figure 4) led to the identification of many new conserved cis-regulatory elements (Table 2 and Figure 6A). Third, we dissected some parts of the above network to identify cell cycle phase-specific control elements to show how the gene regulatory network and the parts-list could be used for generating hypothesis about $S$. pombe cell cycle regulation.

Using new computational strategies and a large gene pool, we constructed a comprehensive parts-list of key regulatory genes, many interesting TFs and binding motifs, and phase-specific modules that offer insights on different aspects of the fission yeast cell cycle regulatory program (see Figure 6 for example). Beyond a core of 500 strongly cell cycle regulated genes in $S$. pombe [25], based on observed transcript oscillation, it has been noted that the number of genes that might be regulated by the cell cycle, due to reasons that are adaptive or otherwise, could be as many as 2000, approximately two-thirds of which may be weakly regulated [6]. Indeed if we observe the ranking of all genes by the variance of their peak phases across ten independent experiments as determined by Marguerat et al. [9], then the top 2000 genes show surprisingly low variance. Thus, to identify a comprehensive set of co-regulated genes that are potentially cell cycle-related, we clustered expression data for a pool of 2000 genes in $S$. pombe having highly consistent cell cycle phase characteristics (see Additional file 8 for the list of the 2000 genes). As described in the Results section, the depth of the pool enabled us to detect new, unexplored modes of transcriptional and post-transcriptional gene regulation in $S$. pombe.
In contrast with previous studies [26], the larger pool size in the present study posed a computational challenge to conventional clustering, which was compounded by the relatively large number of time course and non-time course regulatory experiments. Without the regulatory signatures, solely time course clustering of such a large number of genes produced noisy clusters (data not shown). However, common clustering algorithms that do not distinguish between heterogeneous types of data are more likely to identify primarily the genes with the most consistent periodic profiles across experiments, while identifying the remaining majority of genes as "noisy" and clustering them arbitrarily. To address this, we enhanced the power of detection of an earlier Bayesian coclustering algorithm [15] with the capacity to produce clusters of genes that are co-expressed in many, but not necessarily all of the experiments. Using a mixture of regressions based on the cluster-experiment error variances (see Methods and Additional file 5 Figure S3), the strategy of formalizing the notion of a clustering consensus among independent experiments made our algorithm robust against inter-study variation. As a result, unlike earlier studies that did not use high-throughput data and focused on small-scale networks of biochemical interactions in the $S$. pombe cell cycle $([27,28]$, our approach based on the comprehensive parts-list offers both broad and specific insights.

An ideal window for exploring an interesting phase-specific sub-network is the early M phase, which is the onset of intense regulatory activity involved in mitosis. The regulation by multiple forkhead TFs of different pathways leading to mitosis is well-studied [2,29-31]. Indeed in our NCA, fkh2 displays strong late G2 activity (Figure 1). Recently, Nachman and Regev [10], using a Biochemical Regulatory Network Inference (BRNI) approach, have shown that cell-division specific genes ace 2 and $f k h 2$ act together in a combinatorial regulation way and that $f k h 2$ and sep 1 are involved in a negative feedback loop that may control regulatory activity at the G2/M phase of the fission yeast cell cycle. Interestingly, fkh2 also shows high coordination with SPBC19G7.04 (Figure 1 and Additional file 5 Figure S4), a HMG box TF that is periodically expressed ( $P$ $<10^{-33}$ ) at the onset of $\mathrm{M}$ phase [9,32]. Assuming that TFs with similar TFA profiles might function together [12], it is interesting to check for possible regulatory associations among these factors targeting the $\mathrm{M}$ phase-specific clus- 
A)
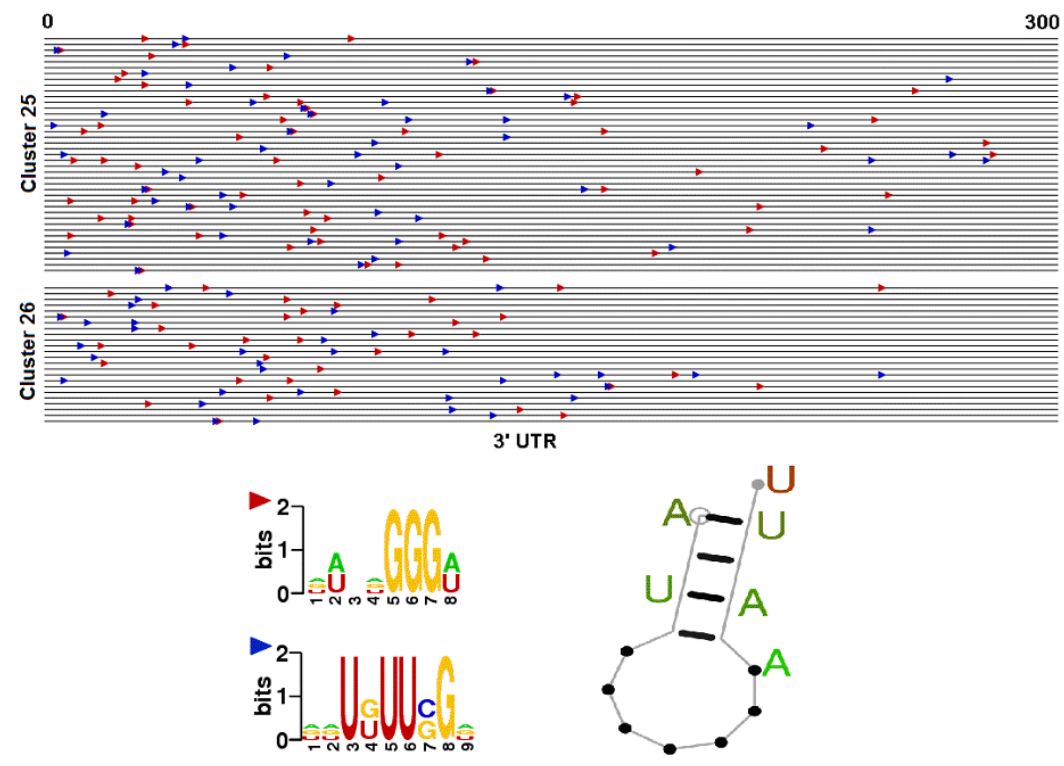

B)

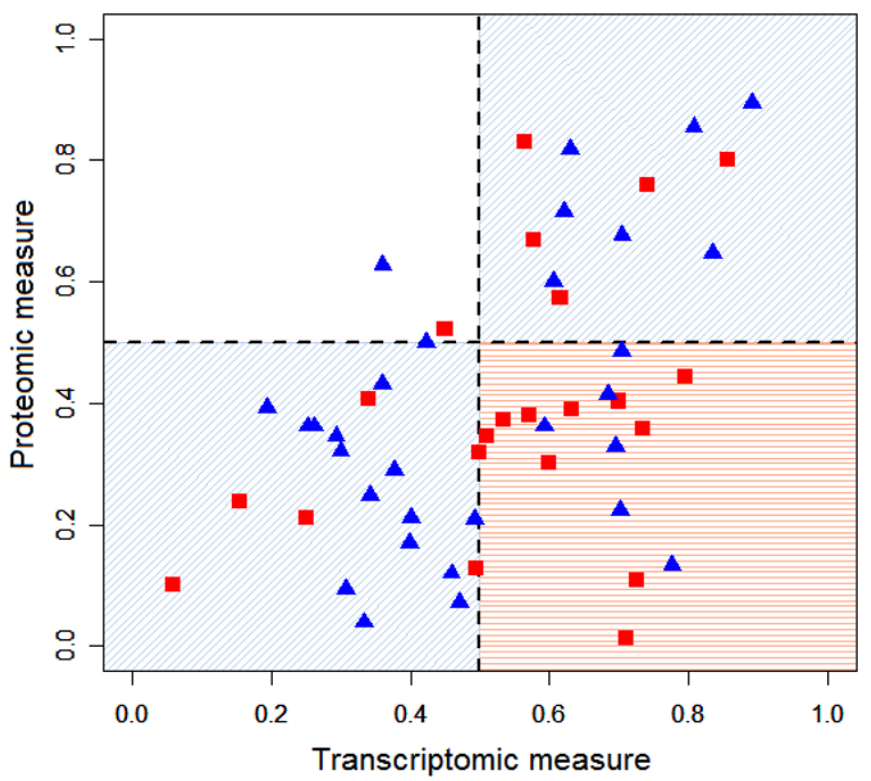

\section{Figure 6}

Post-transcriptional regulation of ribosome biogenesis. A) Genes from the clusters for ribosome biogenesis and related protein assembly and cellular component organization containing statistically significant and conserved RNA motifs in their 3' UTR first 300 bases. The two motifs (see logos) have positional and directional bias and sometimes appear as a combined motif. The genes are listed in the displayed ordering in Table 3. The predicted structure of the motif with the highest likelihood score is also shown. B) Post-transcriptional cis-regulation at these motifs is tested against previously published experimental data [2I]. The red points mark the transcriptomic versus proteomic levels of the genes with the motifs while the blue points depict that for genes from the same clusters without the motifs. 
ters. For instance, a large number of the promoters for genes in cluster 4 (an early mitotic cluster), contained two strong motifs (TGTTTTAC and TGTAWGC) with best matches for binding sites of the forkhead domain (FoxF2, $\left.P<10^{-10}\right)$ and HMG box (HMG-1, $\left.P<0.001\right)$ respectively. Many of these promoters actually contain both types of binding sites, and in opposing-strand orientation, potentially indicative of combinatorial regulation (Additional file 5 Figure S5). While HMG-box TFs are known to associate with forkhead TFs for ribosome biogenesis in S. cerevisiae [33], their dual role with respect to chromatin, which is partly structural and partly regulatory, might be particularly favorable for the intensely active regulation at the onset of mitosis. For instance, besides acting as a conventional TF, some HMG-box TFs can also induce changes in the DNA structure that enhance binding of other TFs [34]. On the other hand, a forkhead TF that binds to condensed chromatin during mitosis could use chromatinremodeling for regulation [35]. In S. cerevisiae, fkh2 not only regulates the G2/M specific clb2 (cyclin B) cluster [36], it also represses $c l b 2$ with the help of a chromatinremodeling ATPase that re-positions nucleosomes in the clb2 promoter [37].

Intriguingly, no systematic study of HMG-box TFs in fission yeast is known although it is the only TF family that has $(60 \%)$ more regulatory members present in $S$. pombe than in $S$. cerevisiae [11]. As a regulatory hub in our predicted early M phase network, SPBC19G7.04 is linked with well-known periodically expressed mitosis and cell division proteins such as klp6 and klp8 (kinesin microtubule motor proteins required for chromosome segregation), some of which also contained both forkhead and HMG-1 motifs in their upstream regulatory sequences (data not shown) and are potential candidates of associated regulation.

While pointing out the gap in $S$. pombe regulatory cascade as compared to $S$. cerevisiae, it was suggested that posttranscriptional regulation might play a major role in the much longer G2 phase of $S$. pombe [8]. With the help of our large gene pool, we focused on two early-to-mid G2 clusters (25 and 26) containing weakly expressed ribosome biogenesis genes. Ribosome biogenesis possibly involves both transcriptional and post-transcriptional steps of gene expression regulation [38], with diverse control elements in budding and fission yeasts [5]. In S. cerevisiae, genes encoding factors involved in ribosomal RNA (rRNA) synthesis and ribosome assembly were among those having the least stable transcripts [39]. Given that orthologous genes could have similar turnover across species [40], it is possible that mRNA stability plays an important, if not critical, role in the multi-layered regulation of ribosome biogenesis genes in S. pombe [23].
Transcript stability is often regulated by specific interactions between cis-elements in the $3^{\prime}$ untranslated region (UTR) of mRNAs and hundreds of different RNA binding proteins (RBPs) in the cell $[41,42]$. Using some of the recently developed resources which specifically search for RNA motifs that may be recognized by different RBPs $[17,43,44]$, we identified highly conserved sequence and structure based RNA motifs in the 3' UTR sequences of 65 ribosome biogenesis genes. Interestingly, these RNA motifs were not significant in the $S$. cerevisiae orthologs of the 65 genes (the only 3' UTR motif reported for nucleolar proteins in the catalog by [43] is GAA.UAUUCA, a distinct motif). Neither were the motifs significant in other gene clusters in $S$. pombe such as the M phase cluster 31 . It is therefore possible that the motifs we identified are bound by proteins that perform highly distinctive (species-, location- and phase-specific) post-transcriptional regulation.

Statistical analysis of the time course profiles of the 65 ribosome biogenesis genes containing the motifs indicated low RNA turnover. Despite the general pattern of their expression -- peaking early in G2 followed by fast decay by mid G2, there were exceptions (Figure 6B and [20]) -- and hence the reported motifs may not have a uniformly destabilizing effect. Therefore, we suspect that with more detailed experiments, further regulatory classification is possible. For instance, several genes containing the RNA motifs (such as lcp5, rrp5, rrp9, utp14, esf2, utp6, utp16) encode small nucleolar U3 RNP (ribonucleoprotein) associated proteins that form parts of a complex involved in rRNA processing and ribosome biogenesis [45]. Indeed post-transcriptional regulation of such a specific functional class has been observed recently [46]. Thus, it is possible that motifs such as those reported above could act as control elements not only for regulating the level, but also the quality of RNA as needed for ribosome biogenesis and other processes in $S$. pombe.

Finally, we understand that like any computational derivation, our gene and module networks are based on modeling assumptions which may not fully capture the complexity of the multi-layered regulatory program of the $S$. pombe cell cycle. While they are based on different types of data from many experiments, the networks could still be enhanced by future studies from various "omic" approaches. For instance, detailed ChIP-on-chip studies, which have greatly enhanced our understanding of the local protein-DNA interactions in S. cerevisiae, could provide similar support to our networks.

\section{Conclusion}

Our fission yeast regulatory network can form the starting point for a variety of inquires. Together with different supporting genome-wide data for the organism such as its sequence [47], proteome [21], localization [48], expres- 
sion intermediates [23], interactome [49], orthology [50], etc., it offers the scope for a wide range of analysis. In particular, as shown above, the underlying parts-list can be mined for insights on different phase-specific regulatory mechanisms involved in the cell cycle. It also provides a basis for generation of plausible hypotheses for experimental investigation. In this direction, we provided new testable evidence for the hypothesis [8] of post-transcriptional regulation of the G2 phase in $S$. pombe in the form of new RNA motifs for the ribosome biogenesis genes. As future work, we are interested to pursue some of the above results experimentally.

\section{Methods \\ Data}

The ten time course microarray experiments on fission yeast cell cycle used in the present study were based on two synchronization methods -- elutriation (Elu) and Cdc25 block-release (Cdc25) -- and referred to as Peng Cdc25 and Peng Elu; Oliva Elut 1 \& 2 and Oliva Cdc25; Rustici Cdc25 1 \& 2 and Elu 1, 2 \& 3. See the previously published work [6-8] for more details. The ten regulatory knockout, overexpression or stress experiments, referred to as Sep1, Sep1p, Nuc2, N-starvation, Cdc25, Cdc22, Cdc10, Cdc10-4hr, Ace2, Ace2p, are also previously described $[6,8]$. The data were normalized by the original experimenters. Therefore, no normalization was performed in this investigation. However, missing values were imputed using the kNNImpute algorithm with the default parameter settings [51]. For post-transcriptional regulation analysis, we used high-throughput proteomic and transcriptomic data for S. pombe from [21], and also the mRNA stability study by [23]. Data on ribosomal occupancy and Codon Adaptation Index were also obtained from [23]. Sequence data for fission yeast Schizosaccharomyces japonicus was obtained from the Fungal Genomes website of Broad Institute of MIT and Harvard University.

\section{Data analysis strategy}

Our data analysis strategy to identify components in the fission yeast regulatory network consists of two parallel workflows. The first is Bayesian co-clustering [15] of the cell cycle and the regulatory gene expression data sets for 2000 periodic genes (see Additional file 5) followed by circular-circular regression (CCR) [16]. For the median profile of each cluster, a random periods model (RPM) [52] was fit. CCR methodology was applied on the estimated phases of all the median profiles across ten experiments to determine the phase coherence of the clusters over the experiments. The details of the clustering algorithm are fully described in Additional file 5. The second workflow used estimated period parameters from the RPM to obtain significant TF-gene pairwise time lagged correlations as priors for Network Component Analysis (NCA) [12]. Using Peng Cdc25 and Peng Elu data sepa- rately, we inferred significant TF activities (TFAs) of $36 \mathrm{TFs}$ during the cell cycle and identified their potential targets (see Additional files 2 and 9 respectively). The activity of a TF is determined by the effect (suitable log-linear decomposition of the gene expression matrix according to the proposed network connectivity) of the TF on its downstream targets as a function of time. The Gene Regulatory Network Inference (GRNInfer) software [53] with default parameter settings $\left(\lambda=0.0\right.$ and threshold $=1 \times 10^{-3}$ controlled the sparseness and the complexity of the network respectively) was used to reconstruct the "consistent" interactions of the 36 TFs with significant activities and the 531 regulatory targets of the TFs based on the five smaller Rustici time course experiments (Elu 1\&2 and Cdc25 1, 2\&3). The contribution of each experiment to the reconstruction of the gene network was weighted by the average signal to noise ratio from the RPM (Additional file 5 Table S1). Consistent interactions are the connections of network nodes that are reproduced reliably in each of the five experiments (see Additional file 3 for the network). Listed below are the details of the models, algorithms and statistics used for the correlation analysis.

\section{Bayesian co-clustering methodology}

In this section, we are not introducing new methodology but pointing out extensions to an earlier algorithm described elsewhere $[15,54]$. We enhanced the algorithm with strategies to co-cluster data from different types of high-throughput experiments. This was achieved by using suitable basis functions to model the individual data types. In particular, we combined time course cell cycle expression data with TF mutant data to identify co-regulated modules. Further, we used a mixture of regressions based on the cluster-experiment error variances to formalize clustering consensus among independent experiments. This allowed the algorithm to produce clusters of genes that are co-expressed in many, but not necessarily all of the experiments thus increasing statistical power and robustness against inter-study variation. For the sake of completeness and reproducibility, we described the methodological details and the steps of the algorithm in Additional file 5 .

\section{TF-gene pairwise time-lagged correlation analysis}

We started with a curated list of 125 known transcription factors in $S$. pombe with identified protein domains [11]. Each TF expression time course was transformed with a sigmoid function:

$$
f\left(x_{i}\right)=\frac{1}{1+\exp \left\{-\left(x_{i}-\bar{x}\right) / s\right\}}, i=1,2, \ldots, N
$$

where $x_{i}$ is relative expression at the $i^{\text {th }}$ time point for a given TF, $\bar{x}$ is the mean of the TF expression profile over all time points and $s$ sis the standard deviation [55] 
assuming that the transformation sufficiently models the activation of a gene by a TF in a nonlinear (sigmodial) fashion.

The time lag correlation between the $j^{\text {th }}$ TF's and $g^{\text {th }}$ gene's time course expression profiles over the first full time period of the cell cycle experiment (which is least affected by loss of phase synchronization, and allows a lag between the activation of the TF and the peak phase of the gene) was computed using Spearman's rank correlation. Let $\phi_{g}$ denote the estimated phase angle of gene and let $T$ (in minutes) denote the estimated cell cycle period of a particular experiment [52]. Then the phase angle for a gene or TF in minutes is given by $t_{g}=\frac{T \varphi_{g}}{2 \pi}$. The TF-gene specific time lag (phase separation) is computed as

$$
L_{j g}= \begin{cases}t_{g}-t_{j} & \text { if } t_{g} \geq t_{j} \\ T+t_{g}-t_{j} & \text { otherwise. }\end{cases}
$$

For $j^{\text {th }}$ TF with intensity values $f\left(x_{i}\right), i=1,2, \ldots, m+1$, and a gene $g$ with expression values $y_{g}=\left(y_{g 1}, y_{g 2}, \ldots, \gamma_{g N}\right)$ the most significant Spearman's rank correlation coefficient $r_{j g}$ is determined between $f\left(x_{i}\right), i=1,2, \ldots, m+1$ and the sub-vector of the full time course of the gene $g$

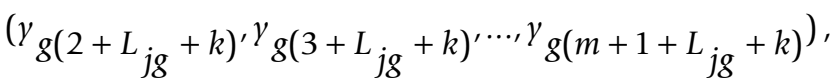
where $m$ is index of the time point corresponding to the first full period of the cell-cycle for the $g^{\text {th }}$ gene over values of the offset $k$, an integer in the "inclusive" range $\{-3, \ldots 3\}$, to account for uncertainty in the determination of the true lag. The significance of each $r_{j g}$ is determined with a twosided $p$-value based on 100,000 random permutations corresponding to the null hypothesis that the TF-gene pair is uncorrelated.

Further criteria were applied to filter out spurious and non-significant TF-gene correlations. First, genes with known peak expression at phase transition points in the cell cycle in $S$. pombe (such as protein-serine/threonine kinase hsk1 required for $S$ phase initiation) were used as demarcations to assess the phase separation between the expression of a TF and the response of a gene. A pair is filtered if its phase separation interval contained demarcation genes from multiple transition points or exceeded 120 degrees. If so, the p-value of that correlation was assigned to 1 . This phase-specificity imposed a biological constraint on the TF-gene pairs, limiting the extent of a TF's regulatory influence based on its phase information. Second, within each of the ten experiments the p-value for every pair was subjected to multiple hypotheses testing with a q-value threshold of 0.05. Only a TF-gene pair with significant correlations (each of $q<0.05$, and having the same sign) in at least a third of the nine experiments was qualified for NCA based on data from the tenth. Assuming a Binomial distribution model, the probability that a TFgene correlation was significant in $\mathrm{k} \geq 3$ of the $\mathrm{n}=9$ experiments by chance alone is 0.0023 . The Peng Cdc25 and Elu data sets were individually held out of the correlation analysis and reserved for separate runs of NCA.

\section{Phase Coherence among multiple experiments}

In this section we are not introducing any new methodology but describing previously published work [16] for completeness sake for reader's convenience so that the paper is self contained. For any given experiment, the phase angle corresponding to cell cycle genes are points on a circle which intrinsically satisfy an (un)known order amongst themselves due to their biological functions. However, due to variability in the underlying data, it is possible that the order of the estimated phase angles of the cell cycle genes may not be same across experiments. If order of the phase angles are preserved across a pair of experiments, then clearly one can align the phase angles of the two experiments by simply rotating the one of the circles and then moving the points within the circle until the two circles are as close to each other as possible. This can be accomplished using circular regression [56]. If there are $k$ cell cycle experiments then one can perform $k$ pairs of circular regressions to align all the circles. Using this principle a methodology was developed [16] with which we could evaluate if a given collection of gene clusters shows phase coherence in multiple independent cellcycle experiments. It is said to be coherent if the ordering of the estimated median phase angles of the clusters across experiments is preserved up to circle-circle regressions. That is, by performing a series of circle-circle regressions, it should be possible to "align" the clusters' phases. A p-value was derived for performing the test using a previously described method [16]. In our analysis of the median values from the clusters of the time course data, one cluster was not represented in the two Peng experiments and therefore was excluded from CCR.

\section{Network Component Analysis and other programs}

To infer transcription factor activities (TFAs), we used the Network Component Analysis (NCA) program [12]. The activity of a TF is the effect (suitable linear combination of the gene expression according to the proposed network connectivity) of the regulator on the downstream targets it controls at a given time point. Since the NCA algorithm allows prior knowledge of the regulation between the $i^{\text {th }}$ gene and $j^{\text {th }} \mathrm{TF}$ to be input as a connectivity matrix, we used only the significant TF-gene correlations from the time lag correlation analysis for this purpose and as follows: 


$$
\text { regulation }_{i j}=\left\{\begin{array}{cc}
+1 & \text { if } r_{i j}>0, \mathrm{q}-\text { value } \leq 0.05 \\
-1 & \text { if } r_{i j}<0, \mathrm{q}-\text { value } \leq 0.05 \\
0 & \text { otherwise }
\end{array}\right.
$$

where +1 is activation, -1 is inhibition and 0 no interaction. The Peng Cdc25 and Elu time course experiments were individually used as the gene expression data input to NCA. Briefly, NCA models gene expression as a function of TFA and the corresponding control strengths (CS) of a transcription factor target interaction. In log-log form the model is written in matrix notation as:

$$
E=A P+\Gamma,
$$

where $\mathrm{E}_{i j}=\log \left(g_{i}\left(t_{j}\right) / g_{i}\left(t_{o}\right), g_{i}\left(t_{j}\right)\right.$ is the expression of $i$-th gene evaluated at time $t_{j}$, A is the regulatory network of control strengths where $\mathrm{A}_{i j}$ denotes the control strength of transcription factor $j$ on gene $i\left(\mathrm{~A}_{i j}=\mathrm{CS}_{i j}\right), \mathrm{P}_{i j}=\log \left(\mathrm{TFA}_{i}\right.$ $\left.\left(t_{j}\right) / \operatorname{TFA}_{i}\left(t_{0}\right)\right)$ with $\operatorname{TFA}_{i}\left(t_{j}\right)$ being the $i$-th transcription factor activity evaluated at time $t_{j}$, and $\Gamma$ represents the noise from the DNA microarray experiment. The dimensions of $\mathrm{E}, \mathrm{A}$ and $\mathrm{P}$ are $(\mathrm{N} \times \mathrm{M}),(\mathrm{N} \times \mathrm{L})$ and $(\mathrm{L} \times \mathrm{M})$, respectively, where $\mathrm{N}$ is the number of genes in the network, $\mathrm{M}$ is the number of data points or experiments conducted, and $\mathrm{L}$ is the number of transcription factors used in the analysis. $\mathrm{TFA}_{i}\left(t_{j}\right)$ and $\mathrm{CS}_{i j}$ are estimated using the regulation (indicator) matrix (equation 3 ), the gene expression data and the Expectation-Maximization (EM) algorithm with an epsilon $=1 \times 10^{-6}$ for conversion. Using the Peng Cdc25 data 39 TFs with TFAs on 784 were obtained and using the Peng Elu data 47 TFs with TFAs on 894 targets were obtained. The intersection of the results from the two NCAs led to the identification of 36 TFs with TFAs (Additional files 2 and 9) on 531 regulatory targets.

The R package CircStats was used to compute circular statistics of the peak phases of genes in every cluster. By coupling gene-wise phase information for 10 experiments with the meta-analyzed list of all genes it was observed that approximately 1,900 genes could be rejected (after FDR adjustment) at significance level 0.05 for the null hypothesis that a gene's phases are uniformly distributed across 10 experiments. The same count increased to more than 2,100 genes when the experiment in which a gene deviated most from its median phase was excluded [57]. Hence we chose the top 2,000 genes in the above list (we computed the circular variance of their phases) for our clustering purposes (for gene list see Additional file 8). A $\mathrm{p}$-value threshold of 0.01 was used for the test of circular uniformity to identify diffuse clusters.

For binding site analysis, BioProspector [58] was used to discover conserved DNA motifs in the upstream regula- tory regions of co-expressed clusters. Only the two most significant motifs per cluster, both with p-value less than $10^{-9}$, were output. No motif was output for a diffuse cluster. A motif clustering program was used to filter the redundant motifs [59] as well as to recognize the previously known motifs $[6,8]$. The following databases were used: protein-protein interactions obtained from BioGRID [49], p-values for periodicity and regulation of expression profiles from Cyclebase.org [32], candidate binding sites from JASPAR [60], and upstream sequences from GeneDB [61]. The DNA motifs were searched against JASPAR with STAMP [62] and plotted with MotifViz [63]. The RNA motifs were identified with FIRE and RNApromo $[17,44]$. Sample skew and sample excess kurtosis of time courses were computed with the R package FinTS. The skew was computed for the first full range of G2 phase in Peng Cdc25 time courses spanning 150-270 min., and the kurtosis for the sub-range $190-270 \mathrm{~min}$. to focus on the right tail. Data on AUG Context Adaptation Index and ribosome occupancy were obtained from [23]. The pvalue of gene expression (Table 3 ) is due to the gene-specific P(reg) entry in Cyclebase.org [32]. The periodicity and dominant Fourier frequency for the $\log _{10}$ (TFA) profiles were determined with Fisher's $g$-statistic (Table 1) and the Average Periodogram (Figure 2) using GeneCycle [13]. The module network (Additional file 4) was computed using four Cdc25 and four Elu data (Oliva Elu 1\&2 not used) with Genomica [64]. Gene Ontology based associations were computed with Genecodis [65].

\section{List of abbreviations}

Cdc25: Cdc25 block-release; CCR: circle-circle regression; CS: control strength; EM: expectation-maximization; Elu: elutriation; GO: Gene Ontology; TF: transcription factor; TFA: transcription factor activity; NCA: network component analysis; GRNInfer: Gene Regulatory Network Inference; rRNA: ribosomal RNA; UTR: untranslated region; RNP: nucleolar ribonucleoprotein; RBPs: RNA binding proteins; RPM: random periods model.

\section{Competing interests}

The authors declare that they have no competing interests.

\section{Authors' contributions}

PRB contributed to the analysis of the time course data to generate TF-Gene correlations, TFAs, circle-circle regression and participated in writing the manuscript. NAH performed the Bayesian clustering. RG performed the motif analyses. LL performed the Gene Ontology analysis. SDP fitted random periods models to estimate phase angles and provided helpful suggestions with the statistical analyses. SP conceived the research project, designed algorithmic strategies and wrote the manuscript. All authors read and approved the final manuscript. 


\section{Additional material}

\section{Additional file 1}

Regulatory targets of the 36 TFs. Regulatory targets of the 36 TFs. Each target is denoted as to whether it was found to be regulated by the TF using NCA and either one or both of the Peng gene expression time course data sets.

Click here for file

[http://www.biomedcentral.com/content/supplementary/17520509-3-93-S1.txt]

\section{Additional file 2}

TFA for 36 TFs based on Peng Cdc25 gene expression time course data. The NCA generated TFAs for the 36 TFs using the Peng Cdc25 gene expression time course data.

Click here for file

[http://www.biomedcentral.com/content/supplementary/17520509-3-93-S2.txt]

\section{Additional file 3}

Gene regulatory network for $\mathrm{S}$. pombe generated from Rustici Cdc25 and Elu gene expression time course data. A directed acyclyic graph (DAG) dot text file containing the interactions between regulatory targets. The network can be opened and viewed with the GVedit function of Graphviz.

Click here for file

[http://www.biomedcentral.com/content/supplementary/17520509-3-93-S3.zip]

\section{Additional file 4}

$M$ and G1 phase regulatory modules. An XML file containing the S pombe $M$ and $G 1$ cell cycle phase regulatory modules. The data can be opened and viewed with the GeneXPress software.

Click here for file

[http://www.biomedcentral.com/content/supplementary/17520509-3-93-S4.zip]

\section{Additional file 5}

Supplemental materials. Supplemental materials containing the Bayesian co-clustering algorithm and supplemental figures and tables.

Click here for file

[http://www.biomedcentral.com/content/supplementary/17520509-3-93-S5.pdf]

\section{Additional file 6}

Cluster assignments. The assignment of each of the top $2000 \mathrm{~S}$. pombe genes (those with highly consistent cell cycle phase characteristics) to a cluster using the Bayesian co-clustering algorithm.

Click here for file

[http://www.biomedcentral.com/content/supplementary/17520509-3-93-S6.txt]

\section{Additional file 7}

Likelihood scores for the occurrence of RNA motifs in the 65 co-regulated genes from clusters \#25 and \#26. The likelihood scores for the occurrence of RNA motifs in the 65 co-regulated genes from clusters \#25 and \#26.

Click here for file

[http://www.biomedcentral.com/content/supplementary/17520509-3-93-S7.txt]

\section{Additional file 8}

The top $2000 \mathrm{~S}$. pombe genes with highly consistent cell cycle phase characteristics. The top $2000 \mathrm{~S}$. pombe genes with the lowest circular variance.

Click here for file

[http://www.biomedcentral.com/content/supplementary/1752-

0509-3-93-S8.txt]

\section{Additional file 9}

TFA for 36 TFs based on Peng Elu gene expression time course data. The NCA generated TFA for the 36 TFs using the Peng Elu gene expression time course data.

Click here for file

[http://www.biomedcentral.com/content/supplementary/17520509-3-93-S9.txt]

\section{Acknowledgements}

Research of PRB, LL and SDP was supported by the Intramural Research Program of the NIH, National Institute of Environmental Health Sciences [ZOI ESI0I744-04]. We thank Jonathan H. Freedman and Reuben Thomas for their review of the manuscript. SP thanks Aviv Regev and Ana Paula Leite for programs on module network analysis. We also dearly thank James $\mathrm{C}$. Liao for his personal communication regarding NCA.

\section{References}

I. Murray AW, Hunt T: The cell cycle: an introduction. New York: W.H. Freeman; 1993.

2. Bahler J: Cell-cycle control of gene expression in budding and fission yeast. Annual review of genetics 2005, 39:69-94.

3. Futcher $B$ : Transcriptional regulatory networks and the yeast cell cycle. Curr Opin Cell Biol 2002, I 4(6):676-683.

4. Bar-Joseph Z, Gerber GK, Lee TI, Rinaldi NJ, Yoo JY, Robert F, Gordon DB, Fraenkel E, Jaakkola TS, Young RA, et al:: Computational discovery of gene modules and regulatory networks. Nature biotechnology 2003, 2 I(I I): 1337-1342.

5. Tanay A, Regev A, Shamir R: Conservation and evolvability in regulatory networks: the evolution of ribosomal regulation in yeast. Proceedings of the National Academy of Sciences of the United States of America 2005, 102(20):7203-7208.

6. Oliva A, Rosebrock A, Ferrezuelo F, Pyne S, Chen H, Skiena S, Futcher B, Leatherwood J: The cell cycle-regulated genes of Schizosaccharomyces pombe. PLoS biology 2005, 3(7):e225.

7. Peng X, Karuturi RK, Miller LD, Lin K, Jia Y, Kondu P, Wang L, Wong LS, Liu ET, Balasubramanian MK, et al.: Identification of cell cycleregulated genes in fission yeast. Molecular biology of the cell 2005 , 16(3): 1026-1042.

8. Rustici G, Mata J, Kivinen K, Lio P, Penkett C], Burns G, Hayles J, Brazma A, Nurse $P$, Bahler J: Periodic gene expression program of the fission yeast cell cycle. Nature genetics 2004, 36(8):809-8I7.

9. Marguerat $S$, Jensen TS, de Lichtenberg $U$, Wilhelm BT, Jensen LJ, Bahler J: The more the merrier: comparative analysis of microarray studies on cell cycle-regulated genes in fission yeast. Yeast (Chichester, England) 2006, 23(4):26I-277.

10. Nachman I, Regev A: BRNI: Modular analysis of transcriptional regulatory programs. BMC bioinformatics 2009, 10:155.

II. Beskow A, Wright AP: Comparative analysis of regulatory transcription factors in Schizosaccharomyces pombe and budding yeasts. Yeast (Chichester, England) 2006, 23( I3):929-935.

12. Liao JC, Boscolo R, Yang YL, Tran LM, Sabatti C, Roychowdhury VP: Network component analysis: reconstruction of regulatory signals in biological systems. Proceedings of the National Academy of Sciences of the United States of America 2003, 100(26): 15522-15527.

13. Wichert S, Fokianos K, Strimmer K: Identifying periodically expressed transcripts in microarray time series data. Bioinformatics 2004, 20(I):5-20. 
14. Schlitt $T$, Brazma A: Current approaches to gene regulatory network modelling. BMC Bioinformatics 2007, 8(Suppl 6):S9.

15. Heard NA, Holmes CC, Stephens DA, Hand DJ, Dimopoulos G: Bayesian coclustering of Anopheles gene expression time series: study of immune defense response to multiple experimental challenges. Proceedings of the National Academy of Sciences of the United States of America 2005, I 02(47):16939-16944.

16. Liu D, Weinberg CR, Peddada SD: A geometric approach to determine association and coherence of the activation times of cell-cycling genes under differing experimental conditions. Bioinformatics (Oxford, England) 2004, 20(16):252I-2528.

17. Elemento $O$, Slonim N, Tavazoie S: A universal framework for regulatory element discovery across all genomes and data types. Mol Cell 2007, 28(2):337-350.

18. Gygi SP, Rochon Y, Franza BR, Aebersold R: Correlation between protein and mRNA abundance in yeast. Mol Cell Biol 1999 , 19(3): 1720-1730.

19. Futcher B, Latter GI, Monardo P, McLaughlin CS, Garrels Jl: A sampling of the yeast proteome. Mol Cell Biol 1999, 19(II):7357-7368.

20. Beyer A, Hollunder J, Nasheuer HP, Wilhelm T: Post-transcriptional expression regulation in the yeast Saccharomyces cerevisiae on a genomic scale. Mol Cell Proteomics 2004, 3(II): 1083-1092.

21. Schmidt MW, Houseman A, Ivanov AR, Wolf DA: Comparative proteomic and transcriptomic profiling of the fission yeast Schizosaccharomyces pombe. Molecular systems biology 2007, 3:79.

22. Greenbaum D, Colangelo C, Williams K, Gerstein M: Comparing protein abundance and mRNA expression levels on a genomic scale. Genome biology 2003, 4(9): II7.

23. Lackner DH, Beilharz TH, Marguerat S, Mata J, Watt S, Schubert F, Preiss $\mathrm{T}$, Bahler J: A network of multiple regulatory layers shapes gene expression in fission yeast. Mol Cell 2007 26(I): I45-I55.

24. Cryer JD, Chan K-S: Time Series Analysis: With Applications in R. NY: Springer; 2008.

25. Jensen LJ, Jensen TS, de Lichtenberg U, Brunak S, Bork P: Co-evolution of transcriptional and post-translational cell-cycle regulation. Nature 2006, 443(7 I II):594-597.

26. Spellman PT, Sherlock G, Zhang MQ, lyer VR, Anders K, Eisen MB, Brown PO, Botstein D, Futcher B: Comprehensive identification of cell cycle-regulated genes of the yeast Saccharomyces cerevisiae by microarray hybridization. Mol Biol Cell 1998, 9(12):3273-3297.

27. Davidich MI, Bornholdt S: Boolean network model predicts cell cycle sequence of fission yeast. PLOS ONE 2008, 3(2):el672.

28. Novak B, Pataki Z, Ciliberto A, Tyson IJ: Mathematical model of the cell division cycle of fission yeast. Chaos 200I, I I (I):277-286.

29. Buck V, Ng SS, Ruiz-Garcia AB, Papadopoulou K, Bhatti S, Samuel JM, Anderson M, Millar JB, Mclnerny CJ: Fkh2p and Seplp regulate mitotic gene transcription in fission yeast. I Cell Sci 2004, I I 7(Pt 23):5623-5632.

30. Bulmer R, Pic-Taylor A, Whitehall SK, Martin KA, Millar JB, Quinn J, Morgan BA: The forkhead transcription factor Fkh2 regulates the cell division cycle of Schizosaccharomyces pombe. Eukaryot Cell 2004, 3(4):944-954.

31. Szilagyi Z, Batta G, Enczi K, Sipiczki M: Characterisation of two novel fork-head gene homologues of Schizosaccharomyces pombe: their involvement in cell cycle and sexual differentiation. Gene 2005, 348:101-109.

32. Gauthier NP, Larsen ME, Wernersson R, de Lichtenberg U, Jensen LJ, Brunak S, Jensen TS: Cyclebase.org--a comprehensive multiorganism online database of cell-cycle experiments. Nucleic acids research 2008:D854-859.

33. Kasahara K, Ohtsuki K, Ki S, Aoyama K, Takahashi H, Kobayashi T, Shirahige K, Kokubo T: Assembly of regulatory factors on rRNA and ribosomal protein genes in Saccharomyces cerevisiae. Molecular and cellular biology 2007, 27(19):6686-6705.

34. Bustin M: Regulation of DNA-dependent activities by the functional motifs of the high-mobility-group chromosomal proteins. Molecular and cellular biology 1999, 19(8):5237-5246.

35. Yan J, Xu L, Crawford G, Wang Z, Burgess SM: The forkhead transcription factor Foxll remains bound to condensed mitotic chromosomes and stably remodels chromatin structure. Molecular and cellular biology 2006, 26(I): 155-168.

36. Koranda M, Schleiffer A, Endler L, Ammerer G: Forkhead-like transcription factors recruit Ndd I to the chromatin of G2/M-specific promoters. Nature 2000, 406(6791):94-98.

37. Sherriff JA, Kent NA, Mellor J: The Isw2 chromatin-remodeling ATPase cooperates with the Fkh2 transcription factor to repress transcription of the B-type cyclin gene CLB2. Molecular and cellular biology 2007, 27(8):2848-2860.

38. Henras AK, Soudet J, Gerus M, Lebaron S, Caizergues-Ferrer M, Mougin A, Henry Y: The post-transcriptional steps of eukaryotic ribosome biogenesis. Cell Mol Life Sci 2008, 65( (15):2334-2359.

39. Grigull J, Mnaimneh S, Pootoolal J, Robinson MD, Hughes TR: Genome-wide analysis of mRNA stability using transcription inhibitors and microarrays reveals posttranscriptional control of ribosome biogenesis factors. Molecular and cellular biology 2004, 24( I 2):5534-5547.

40. McCarroll SA, Murphy CT, Zou S, Pletcher SD, Chin CS, Jan YN, Kenyon C, Bargmann $\mathrm{Cl}$, $\mathrm{Li} \mathrm{H}$ : Comparing genomic expression patterns across species identifies shared transcriptional profile in aging. Nat Genet 2004, 36(2): 197-204.

4I. Foat BC, Houshmandi SS, Olivas WM, Bussemaker HJ: Profiling condition-specific, genome-wide regulation of mRNA stability in yeast. Proceedings of the National Academy of Sciences of the United States of America 2005, I 02(49): 17675- 17680.

42. Gerber AP, Herschlag D, Brown PO: Extensive association of functionally and cytotopically related mRNAs with Puf family RNA-binding proteins in yeast. PLoS Biol 2004, 2(3):E79.

43. Shalgi R, Lapidot M, Shamir R, Pilpel Y: A catalog of stability-associated sequence elements in $3^{\prime}$ UTRs of yeast mRNAs. Genome Biol 2005, 6( I 0):R86.

44. Rabani M, Kertesz M, Segal E: Computational prediction of RNA structural motifs involved in posttranscriptional regulatory processes. Proc Natl Acad Sci USA 2008, 105(39): I 4885-I 4890.

45. Dragon F, Gallagher JE, Compagnone-Post PA, Mitchell BM, Porwancher KA, Wehner KA, Wormsley S, Settlage RE, Shabanowitz J, Osheim Y, et al:: A large nucleolar U3 ribonucleoprotein required for $18 \mathrm{~S}$ ribosomal RNA biogenesis. Nature 2002, 4I 7(6892):967-970.

46. Nabavi S, Nellimarla S, Nazar RN: Post-transcriptional regulation of the U3 small nucleolar RNA. The Journal of biological chemistry 2008, 283(3 I):2|404-2|4|0.

47. Wood V, Gwilliam R, Rajandream MA, Lyne M, Lyne R, Stewart A, Sgouros J, Peat N, Hayles J, Baker S, et al.: The genome sequence of Schizosaccharomyces pombe. Nature 2002 415(6874):87|-880.

48. Matsuyama A, Arai R, Yashiroda $Y$, Shirai A, Kamata A, Sekido $S$, Kobayashi Y, Hashimoto A, Hamamoto M, Hiraoka Y, et al:: ORFeome cloning and global analysis of protein localization in the fission yeast Schizosaccharomyces pombe. Nat Biotechnol 2006, 24(7):84I-847.

49. Breitkreutz BJ, Stark C, Reguly T, Boucher L, Breitkreutz A, Livstone M, Oughtred R, Lackner DH, Bahler J, Wood V, et al.: The BioGRID Interaction Database: 2008 update. Nucleic Acids Res 2008:D637-640

50. Penkett C], Morris JA, Wood V, Bahler J: YOGY: a web-based, integrated database to retrieve protein orthologs and associated Gene Ontology terms. Nucleic Acids Res 2006:W330-334.

51. Troyanskaya O, Cantor M, Sherlock G, Brown P, Hastie T, Tibshiran $R$, Botstein D, Altman RB: Missing value estimation methods for DNA microarrays. Bioinformatics (Oxford, England) 200I, I 7(6):520-525

52. Liu D, Umbach DM, Peddada SD, Li L, Crockett PW, Weinberg CR: $A$ random-periods model for expression of cell-cycle genes. Proceedings of the National Academy of Sciences of the United States of America 2004, I0I( I 9):7240-7245.

53. Wang $Y$, Joshi T, Zhang XS, Xu D, Chen L: Inferring gene regulatory networks from multiple microarray datasets. Bioinformatics 2006, 22(19):2413-2420.

54. Heard NA, Holmes CC, Stephens DA: A quantitative study of gene regulation involved in the immune response of anopheline mosquitoes: An application of Bayesian hierarchical clustering of curves. Journal of the American Statistical Association 2006, $101(473): 18-29$.

55. Chen HC, Lee HC, Lin TY, Li WH, Chen BS: Quantitative characterization of the transcriptional regulatory network in the 
yeast cell cycle. Bioinformatics (Oxford, England) 2004, 20(12): 19|4-1927.

56. Downs TD, Mardia KV: Circular regression. Biometrika 2002, 89(3):683-697.

57. Pyne S, Gutman R, Kim CS, Futcher B: Phase coupled meta-analysis: sensitive detection of oscillations in cell cycle gene expression, as applied to fission yeast. BMC Genomics 2009 in press.

58. Liu X, Brutlag DL, Liu JS: BioProspector: discovering conserved DNA motifs in upstream regulatory regions of co-expressed genes. Pacific Symposium on Biocomputing 200I:127-138.

59. Jensen ST, Liu JS: Bayesian clustering of transcription factor binding motifs. Journal of the American Statistical Association 2008, I 03(48I): I88-200.

60. Sandelin A, Alkema W, Engstrom P, Wasserman WW, Lenhard B: JASPAR: an open-access database for eukaryotic transcription factor binding profiles. Nucleic acids research 2004:D9I-94.

61. Hertz-Fowler C, Peacock CS, Wood V, Aslett M, Kerhornou A, Mooney P, Tivey A, Berriman M, Hall N, Rutherford K, et al: GeneDB: a resource for prokaryotic and eukaryotic organisms. Nucleic acids research 2004:D339-343.

62. Mahony S, Benos PV: STAMP: a web tool for exploring DNAbinding motif similarities. Nucleic acids research 2007:W253-258.

63. Fu Y, Frith MC, Haverty PM, Weng Z: MotifViz: an analysis and visualization tool for motif discovery. Nucleic acids research 2004:W420-423.

64. Segal E, Shapira M, Regev A, Pe'er D, Botstein D, Koller D, Friedman $\mathrm{N}$ : Module networks: identifying regulatory modules and their condition-specific regulators from gene expression data. Nature genetics 2003, 34(2): $166-176$.

65. Carmona-Saez P, Chagoyen M, Tirado F, Carazo JM, Pascual-Montano A: GENECODIS: a web-based tool for finding significant concurrent annotations in gene lists. Genome Biol 2007, 8(I):R3.

Publish with Biomed Central and every scientist can read your work free of charge

"BioMed Central will be the most significant development for disseminating the results of biomedical research in our lifetime. "

Sir Paul Nurse, Cancer Research UK

Your research papers will be:

- available free of charge to the entire biomedical community

- peer reviewed and published immediately upon acceptance

- cited in PubMed and archived on PubMed Central

- yours - you keep the copyright 